\title{
Keeping Your Head On Target
}

\author{
Aasef G. Shaikh, ${ }^{1,7}$ Aaron L. Wong, ${ }^{2,3}$ David S. Zee, ${ }^{3,4,5,6}$ and H. A. Jinnah ${ }^{7,8,9}$ \\ ${ }^{1}$ Department of Neurology, Case Western Reserve University, Cleveland, Ohio, ${ }^{2}$ Department of Biomedical Engineering, The Johns Hopkins University, \\ Baltimore, Maryland, Departments of ${ }^{3}$ Neurology, ${ }^{4}$ Otolaryngology, ${ }^{5}$ Ophthalmology, and ${ }^{\circ}$ Neuroscience, The Johns Hopkins University, School of \\ Medicine, Baltimore, Maryland, and Departments of ${ }^{7}$ Neurology, ${ }^{8}$ Human Genetics, and ${ }^{9}$ Pediatrics, Emory University, Atlanta, Georgia 30322
}

The mechanisms by which the human brain controls eye movements are reasonably well understood, but those for the head less so. Here, we show that the mechanisms for keeping the head aimed at a stationary target follow strategies similar to those for holding the eyes steady on stationary targets. Specifically, we applied the neural integrator hypothesis that originally was developed for holding the eyes still in eccentric gaze positions to describe how the head is held still when turned toward an eccentric target. We found that normal humans make head movements consistent with the neural integrator hypothesis, except that additional sensory feedback is needed, from proprioceptors in the neck, to keep the head on target. We also show that the complicated patterns of head movements in patients with cervical dystonia can be predicted by deficits in a neural integrator for head motor control. These results support ideas originally developed from animal studies that suggest fundamental similarities between oculomotor and cephalomotor control, as well as a conceptual framework for cervical dystonia that departs considerably from current clinical views.

\section{Introduction}

Vision is the most important sense by which we relate ourselves to our external environment. For optimal vision, the brain has mechanisms that allow us to fix the eyes on a stationary target, to smoothly track moving targets, and to make saccades that rapidly redirect the eyes toward new objects. Many of the neural circuits controlling these eye movements are well understood (Leigh and Zee, 2006).

For horizontal saccades, circuits in the pons generate phasic, velocity commands that overcome orbital viscous forces to move the eyes rapidly to a new position (Luschei and Fuchs, 1972). The velocity commands are mathematically integrated by neurons in the rostral medulla into a tonic position command to counteract elastic restoring forces so that the eyes remain on target (Robinson, 1968, 1981; Cannon and Robinson, 1987; Cheron and Godaux, 1987). Separate neural integrator circuits in the midbrain control vertical saccades (King et al., 1981; Fukushima, 1987; Crawford et al., 1991). However, all of these integrators are inherently "leaky," resulting in centripetal drift of the eyes back to a null position near the midline. A feedback system through the cerebellum improves gaze-holding (Robinson, 1974; Zee et al., 1980, 1981), and cerebellar lesions cause gaze-evoked nystagmus, which is char-

Received July 17, 2012; revised May 21, 2013; accepted May 27, 2013.

Author contributions: A.G.S., D.S.Z., and H.A.J. designed research; A.G.S., A.L.W., and H.A.J. performed research; A.G.S., A.L.W., D.S.Z., and H.A.J. analyzed data; A.G.S., A.L.W., D.S.Z., and H.A.J. wrote the paper.

This work was supported in part by grants from the Gustavus and Louise Pfeiffer Foundation, Fellowship support from Allergan, Inc., and NIH Grants EY01849, NS040470, and NS065701. We thank Mr. Dale Roberts for technical assistance and Drs. Mahlon DeLong, Thomas Wichmann, and Stewart Factor for comments on this manuscript.

The authors declare no competing financial interests.

Correspondence should be addressed to Dr. Aasef G. Shaikh, 6300 Woodruff Memorial Building, Department of Neurology, Emory University School of Medicine, 101 Woodruff Circle, Atlanta, GA 30322. E-mail: aasefshaikh@gmail.com.

DOI:10.1523/JNEUROSCI.3415-12.2013

Copyright $\odot 2013$ the authors $\quad 0270-6474 / 13 / 3311281-15 \$ 15.00 / 0$ acterized by repetitive cycles of drifts away from the target, followed by rapid corrections back toward the target. The ocular motor neural integrator principle helps to understand how the eyes are directed to a target and kept there, and to understand abnormalities such as gaze-evoked nystagmus.

The control of gaze not only involves movements of the eyes, but also movements of the head. These movements typically occur together to change the line of sight, although eye and head movements can be dissociated (Collins and Barnes, 1999). The central mechanisms controlling head movements are less well understood than those of the eyes, but studies in animals have implied that the brain has evolved mechanisms for head control that are similar to those of the eyes (Freedman and Sparks, 1997a, b; Ceylan et al., 2000; Corneil et al., 2002; Klier et al., 2002; Peterson, 2004; Liao et al., 2005; Farshadmanesh et al., 2007; Gandhi and Sparks, 2007; Klier et al., 2007; Gandhi et al., 2008). More specifically, neural circuits in the interstitial nucleus of Cajal and the nearby nucleus of Darkschewitsch appear to serve as a neural integrator responsible for keeping the head steady when it is turned toward an eccentric target (Hassler and Hess, 1954; Malouin and Bédard, 1982; Klier et al., 2002, 2007; Farshadmanesh et al., 2007). Dysfunction of these circuits may underlie abnormal head movements in certain human diseases.

Here, we address two fundamental questions about the control of head movements in humans. The first is whether the neural integrator hypothesis can predict behaviors of healthy human subjects when they turn their head toward eccentric targets and attempt to hold it steadily on target. The second is whether dysfunction of a head neural integrator can explain abnormal head movements in patients with cervical dystonia (CD, also known as torticollis), a poorly understood disorder characterized by difficulties with controlling and maintaining head positions (Dauer et al., 1998; Singer and Velickovic, 2008). 


\section{Materials and Methods}

Subjects. The study was approved by The Johns Hopkins University Institutional Review Board. All subjects gave informed consent. The healthy control group included 11 subjects ( 4 women and 7 men), while the CD group had 14 subjects (13 women and $1 \mathrm{man}$ ). No effort was made to recruit CD patients with a specific pattern of head movements, to avoid the risk that a particular subtype might limit generalization of the results. All subjects had normal visual acuity with corrective lenses. On clinical examination, eye movements were normal, including saccades and steady eccentric gaze holding. All CD patients were being treated with botulinum toxin. Measurements were performed at treatment nadirs, within 1 week before the next scheduled treatment. None were taking other oral medications for tremor or dystonia at the time of testing. We excluded patients with CD who had a known or presumed cause, patients with broader involvement suggestive of segmental or generalized dystonia, and patients with other motor signs suggestive of a more widespread neurodegenerative disorder.

Head movement recordings. Head positions were recorded in a darkened room using the magnetic field search coil technique with a dual (three-dimensional) search coil (Skalar Medical) mounted on a bite bar. Subjects sat within a stationary frame that held the external magnetic field coils. Each subject bit tightly on a bar that was custom molded from dental impression material. A headband with a laser pointer was mounted on the forehead. To establish a baseline reference position for the head, another laser was mounted on the wall in front of the subject and the head was centered in the magnetic field by aligning a vertical and horizontal beam from the wall-mounted laser on the subject's nasion. The intersection of two orthogonally directed laser beams was aligned with the center of the coil frame. Head movements were recorded in the horizontal, vertical, and torsional planes. Horizontal head movements were defined as those around an earth vertical axis passing through the center of the coil frame (i.e., turning the chin to the right or left, also called torticollis). Vertical head movements were those around an earth horizontal axis, passing through the center of the coil frame (i.e., flexion and extension of the head, also called anterocollis or retrocollis). Torsional head movements were those around an earth horizontal axis passing through the center of the coil frame and parallel to the naso-occipital axis of the head (i.e., tilting the head toward the shoulder, also called laterocollis). Although head movements naturally are best expressed in Fick coordinates (Klier et al., 2007), we focused here on rotation of the head to horizontal eccentricities.

Eye movement recordings. Two-dimensional eye movements from one eye also were recorded with the magnetic search coil technique (Chronos Vision). Search coil annuli were calibrated and then placed on the eye after local anesthesia with oxybuprocaine $0.4 \%$. Calibrations and recordings were conducted in complete darkness except for specific visual targets as previously described (Bergamin et al., 2001). The search coil signals measuring eye and head movements were hardware filtered with a single pole RC filter with bandwidth of $0-90 \mathrm{~Hz}$, and then sampled at $1000 \mathrm{~Hz}$ with 12-bit resolution. Data were processed in Matlab (MathWorks).

Experimental design. Each subject was evaluated under four different conditions. In the first condition (LED plus laser) subjects were placed in a dark room to minimize visual feedback. An array of LEDs was positioned $\sim 3 \mathrm{~m}$ in front of the subject, with targets appearing at the center, or to the right or left at $10^{\circ}, 20^{\circ}$, and $30^{\circ}$. The subjects were instructed to aim the head toward a central LED that was illuminated, then rapidly move the head when the center target was turned off and a newly illuminated target appeared to the right or left. The laser beam projector mounted on the forehead provided visual feedback, permitting subjects to correct head positions by superimposing the head-fixed laser beam on the target LED. The laser eliminated the possibility that eye movements could compensate for imprecise head position (Guitton et al., 1986).

In the second condition (LED without laser), subjects were asked to turn their heads rapidly in the horizontal plane toward the LED target in a dark room with the head-fixed laser turned off. This condition was designed to remove visual feedback regarding the accuracy of head position with respect to the target. In the absence of visual feedback, the accuracy of head position must rely on neck muscle proprioception, vestibulo-collic reflex, and cervico-collic reflexes (Peterson et al., 1985). However, in humans the vestibulo-collic reflex is ineffective when the head is fixed on a target or moving very slowly (Guitton et al., 1986; Keshner and Peterson, 1995). Thus, in the absence of visual feedback, when the subject was asked to aim the head toward an eccentrically placed target, head stabilization primarily relies on proprioceptive signals from neck muscles.

In the third condition (LED plus vibration without laser), the subjects were also asked to aim their heads at a continuously illuminated LED target in a dark room without the laser, but vibration with a sinusoidal waveform at $50 \mathrm{~Hz}$ frequency and $0.5^{\circ}$ amplitude was applied at the same time over the dorsal processes of the cervical spine to distort proprioceptive signals from neck muscles (Burke et al., 1976; Kaji et al., 1995).

In the fourth condition (LED plus laser and vibration), the subjects were asked to turn their heads toward the LED target in a dark room, with the head-fixed laser to provide visual feedback regarding the accuracy of head position, but also with vibration to distort proprioceptive signals from neck muscles.

Relationship between eye-in-orbit position and head movements. An important goal of these experiments was to assess the influence of perturbations in the visual and proprioceptive inputs on head holding. However, the position of the eye in the orbit may influence head movements. Therefore, eye and head positions were simultaneously measured in seven healthy subjects. For each experimental condition, a shift in the LED target first caused an eye saccade, followed by a head saccade. When the head-fixed laser was turned off, when the head drifted away from the target, the eyes remained on the LED target. The eye movement fixation response could be either a visual-following or vestibulo-ocular reflex. When the head-fixed laser was turned on, regardless of horizontal head orientation, the position of the eye in the orbit when looking at a continuously illuminated LED target with a laser attached to the head remained stable. The position of the eye in the orbit was measured during epochs of various head orientations in all subjects. The average position of the eye in the orbit, during all recording epochs in all subjects, indicating the variability in eye positions around the target, was $0.9 \pm 1.0^{\circ}$ (mean \pm SD) without neck vibration. When neck vibration was added the average position of the eye in the orbit increased to $1.5 \pm 1.0^{\circ}$ (mean \pm SD). Such small variations in eye position would likely be too small to generate meaningful feedback about the position of the eyes in the orbit that in turn could be used to control head position (Gauthier et al., 1990a, b). $\mathrm{CD}$ patients with tonic head deviation at baseline had compensatory offsets in eye positions while viewing the center target. Similar to prior studies, CD patients had no difficulties generating accurate saccades or maintaining stable ocular fixation during eccentric positions (Stell et al., 1990). As a result, all remaining normal subjects and CD patients were evaluated without simultaneous eye movement measurements and focused instead on head movements.

Data analysis. The angular position of the search coil with respect to the magnetic fields was digitized at $1000 \mathrm{~Hz}$ and the data were processed to compute head positions in three dimensions using Matlab (MathWorks). Head positions were computed from smoothed three-dimensional rotation vectors. Most patients with $\mathrm{CD}$ had relatively high-frequency sinusoidal head oscillations that were superimposed on drifts in head position. For the analysis of movements involving drift of the head away from the LED target, the raw signal was filtered first to remove the high-frequency sinusoidal oscillations and to identify epochs of head drifts, using a Matlab algorithm that implements the Savitzky-Golay filter. In most cases in which the sinusoidal oscillations superimposed upon the drifts were minimal, the filter frame length was kept at 21 . In occasional cases where the drift had a robust superimposed sinusoidal modulation, the frame length was increased to 101. The same frame length was used to analyze data at all eccentricities in a given patient. The value of the polynomial order of the filter was kept at three. Head saccades and quick phase velocities, however, were always analyzed unfiltered. The analysis scheme is summarized in Figure 1.

The beginnings and endings of head drifts were interactively identified on the horizontal head position trace. In some instances, a brief rapid head movement in the opposite direction followed the initial rapid shifts of the head to the new position. In such instances, the beginning of the 
A Raw head position data
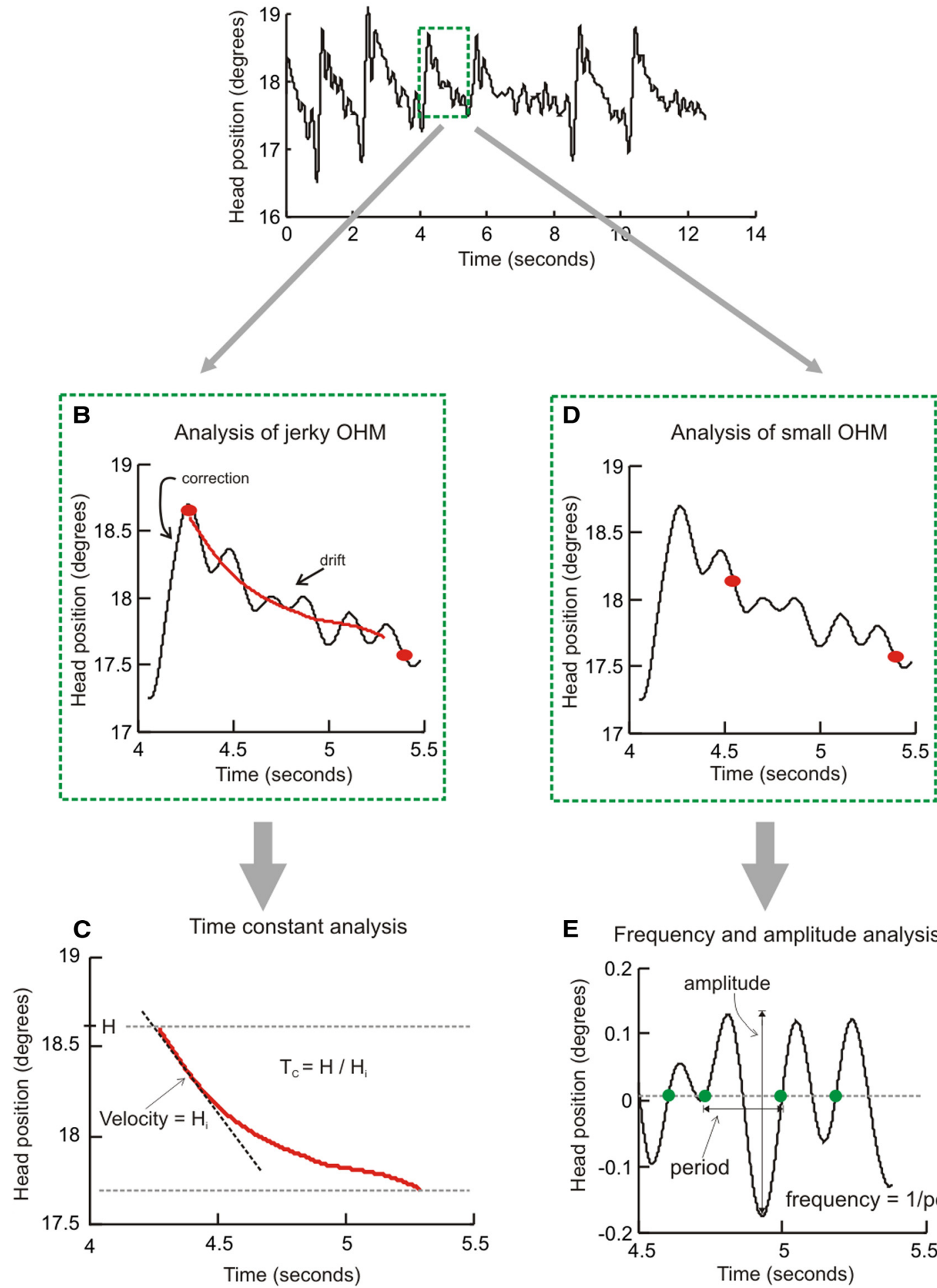

E Frequency and amplitude analysis

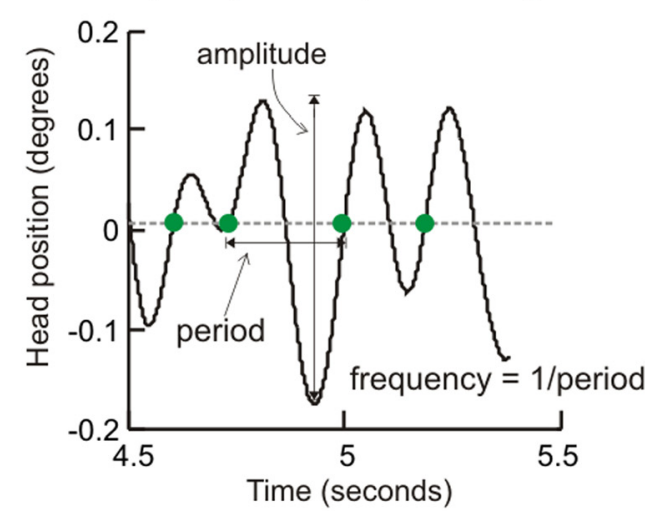

Figure 1. Schematic for data analysis. A depicts typical raw head position data from a CD patient. The head position waveform had high amplitude jerky head oscillations and superimposed small sinusoidal oscillations. The first step was to interactively select a region of interest (green box in $A$ ). To analyze the large jerky oscillatory head movements, we identified drift of the head position in the region of interest between two red dots $(\boldsymbol{B})$. The signal was then subject to a Savitzsky-Golay filter, and the time constant of drift in filtered head position was computed ( $(\boldsymbol{C}$. To analyze the smaller sinusoidal oscillatory movements, the region of interest between two red dots $(\boldsymbol{D})$ within the region of interest in the green box $(\boldsymbol{A})$ was interactively selected and detrended $(\boldsymbol{E})$. Time points of intersection of zero-line and the signal moving from negative to positive were determined. The difference of these time points was considered as period of oscillation, and the oscillation frequency was determined as the inverse of the time period. $\mathrm{H}$, Initial head position; Hi, Initial head velocity; $\mathrm{Tc}$, decay time constant; $\mathrm{OHM}$, oscillatory head movements.

drift was measured from the end of this rapid backward movement. In most instances, when such rapid movements were absent, the beginning of the drift was identified immediately after the end of the rapid head movement. The epochs of head positions encompassing the drifts were further differentiated to compute drift velocity and divided into three equal segments. The median velocity of the first segment was used as initial head velocity. The same analysis technique was used to compute the velocity of rebound drifts that occurred after return to the straight- 
ahead position. The ratio of initial head position and initial head velocity was used to determine the decay time constant (Fig. 1C). Since measurements of the time constant require relatively long epochs of sustained head drifts, they were restricted to the second and third experimental conditions (LED only and LED plus neck vibration) in healthy subjects and to LED only in patients with CD. The time constant was measured individually for the drift after every head movement in each subject.

Small oscillatory head movements. Nonfiltered head position data were used for the analysis of small sinusoidal head oscillations when they were present. Epochs of head position was first detrended to remove drifts in head positions and then normalized with mean head position. This permitted data to be realigned along the abscissa such that the peaks of the cycles remained positive and the troughs negative. Cycle-by-cycle analysis was performed on detrended head positions. The $x$-coordinates of the intersection of the data trace with the abscissa (moving from the negative value to the positive value) were determined. The $x$-coordinate of the first data point that crossed the abscissa marked the beginning and the subsequent data point marked the end of the cycle. With this definition of a cycle, we then computed its width. The inverse of the cycle width yielded the cycle frequency and the difference between the peak and trough yielded the cycle amplitude. This method is schematized in Figure $1, D$ and $E$.

\section{Results}

\section{Voluntary head movements in healthy subjects}

In the first test condition, all 11 healthy subjects were able to make rapid head movements (head saccades) and aim the headfixed laser in a darkened room toward illuminated LED targets at the center, or to the right or left at $10^{\circ}, 20^{\circ}$, and $30^{\circ}$. They also were able to maintain stable head positions toward the target at all orientations tested (Fig. 2A-C). The amplitudes and velocities of head movements when holding the head steady at all tested orientations were very small (Fig. $2 B, C$, Table 1 ). The relationships of horizontal head velocities and amplitude to degree of head eccentricity were characterized by linear fit, where smaller values of head velocity slopes reflect smaller drifts with change in position. The mean slope of this line was $-0.0001 \pm 0.0001$ for amplitude and $0.0003 \pm 0.001 \mathrm{~s}^{-1}$ for velocity. Head velocities along the vertical and torsional axes were also measured during eccentric horizontal head holding. Similar linear fit revealed velocity slopes of $0.002 \pm 0.006 \mathrm{~s}^{-1}$ and $0.0003 \pm 0.002 \mathrm{~s}^{-1}$ along the torsional and vertical axes, respectively (Table 2 ).

In the second test condition with the head-fixed laser turned off to reduce visual feedback regarding the accuracy of head position, all healthy subjects were able to keep their heads stable at the midline (null position). They also were able to make head saccades toward horizontal eccentric targets, but centripetal horizontal drifts of the head began immediately after the head reached the target (Fig. 2D). Horizontal drift amplitudes and velocities increased when the head was turned farther away from the null. The horizontal drift amplitude and eccentric head position had a linear relationship with a slope of $-0.03 \pm 0.01$ (mean $\pm \mathrm{SD}$, Fig. $2 E$ ). The drift velocity and eccentricity also had a linear relationship with a slope $-0.008 \pm 0.003 \mathrm{~s}^{-1}$ (mean \pm $\mathrm{SD}$, Fig. $2 F$ ). All fitted lines intercepted with the $x$-axis near the zero position (straight ahead position), which was the null position. The mean value of the intercept with the $x$-axis was $0.001 \pm$ 0.09 degrees. The linear relationship of the drift velocity and horizontal head position with a negative slope and near-zero intercept suggests that head drifts were consistently toward midline, with increasing eccentricity associated with increasing centripetal drift velocity. There were no drifts in torsional and vertical head position during eccentric horizontal head positions. As a result the torsional and vertical head velocity was minimal and their linear relation to eccentric horizontal head position revealed slopes of $-0.0002 \pm 0.0007 \mathrm{~s}^{-1}$ and $0.0006 \pm 0.0001$ $\mathrm{s}^{-1}$, respectively (Table 2 ). The slopes for horizontal drift velocity were significantly larger as compared with vertical and torsional velocities ( $t$ test, $p<0.0001$ for both directions).

In the third test condition, the head-fixed laser remained off, the LED target remained on, but in addition the area over the dorsal processes of the cervical spine was vibrated to distort proprioceptive signals from neck muscles. Head holding again was stable at midline for all healthy subjects. However, the centripetal drifts of the head from eccentric head positions were exaggerated, with increased drift amplitudes and velocities compared with the second condition without vibration (Fig. $2 G-I$, Table 1 ). The linear relationship between the horizontal drift amplitude and eccentric horizontal head position revealed a slope of $-0.22 \pm$ 0.02 (Fig. 2H, Table 1). The linear relationship between the horizontal drift velocities versus degrees of horizontal eccentricity had a mean slope of $-0.015 \pm 0.003 \mathrm{~s}^{-1}$ (Fig. 2I, Table 1). The analysis suggests that head drifts are present, directed toward the central null, but are much more prominent with vibration. The linear fit relating the horizontal drift velocity to degree of horizontal eccentricity intercepted the $x$-axis at $-0.13 \pm 0.16$ degrees, suggesting the straight-ahead null position. Similarly to the second condition, the drifts along orthogonal axes were minimal during horizontal eccentric head holding. The slopes of the linear fit relating torsional and vertical drift velocities with horizontal eccentric head positions were $0.001 \pm 0.001 \mathrm{~s}^{-1}$ and $0.002 \pm 0.003 \mathrm{~s}^{-1}$, respectively (Table 2 ). These values were significantly smaller compared with horizontal drift velocity $(t$ test, $p<0.0001)$.

The fourth test condition also included vibration but the head-fixed laser was turned on so that subjects had visual feedback regarding the inaccuracy of head positions. Under these conditions, the head remained stable at midline, but again drifted from eccentric targets toward the midline. However, the visual feedback from the laser made subjects aware of the inaccurate head position, resulting in repetitive corrective horizontal movements that returned the head toward its intended target (Fig. 2J). Horizontal drift velocities were comparable to the condition without the head-fixed laser, but drift amplitudes were smaller due to the frequent corrections (Table 1). The mean slope of the linear fit comparing the drift amplitude and horizontal eccentricity was $-0.02 \pm 0.008$ (Fig. $2 K$, Table 1 ). The mean slope of the linear fit depicting the relationship of the horizontal drift velocity with eccentric horizontal head position was $-0.01 \pm 0.002 \mathrm{~s}^{-1}$ (Fig. 2L, Table 1). The mean intercept of the fitted lines with the $x$-axis was $0.02 \pm 0.1$ degrees, again suggesting a central null position. There were no drifts in vertical and torsional head positions under these conditions. The mean slopes of the fitted line that compare torsional and vertical drifts with horizontal head eccentricities were $0.008 \pm 0.007 \mathrm{~s}^{-1}$ and $-0.003 \pm 0.008 \mathrm{~s}^{-1}$, respectively (Table 2 ). The slopes of the line relating orthogonal, vertical, and torsional drifts with horizontal eccentricity were significantly smaller than the slope representing the horizontal drifts ( $t$ test, $p<0.02$ )

From eccentric positions the head drifted centripetally with a velocity that had an approximately exponentially decaying waveform. This phenomenon was most obvious when drift amplitudes were relatively large, specifically in the condition with an LED target but no laser, with or without neck vibration (Fig. $2 D, G)$. To quantify further the horizontal drifts, we measured the decay time constant of horizontal drifts. The decay time constant is a measure of the rate of change of head position assuming 
A Head-fixed laser plus LED target

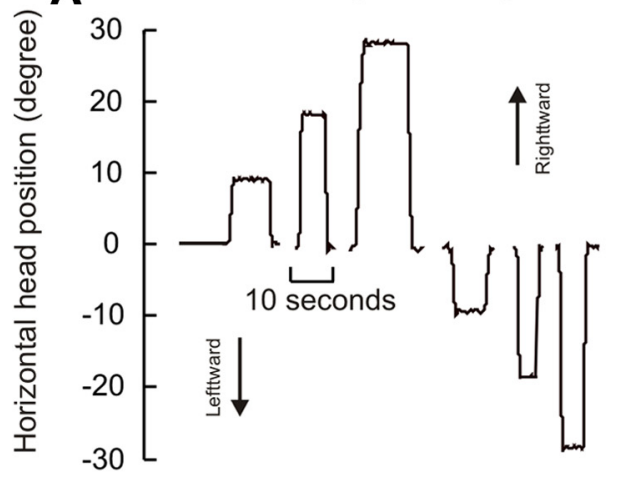

D

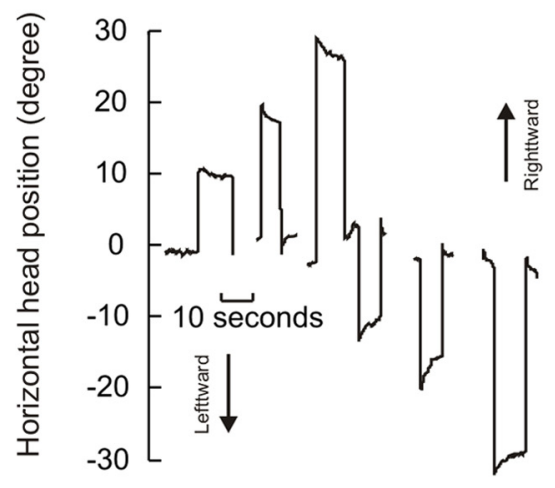

G LED target plus neck vibration
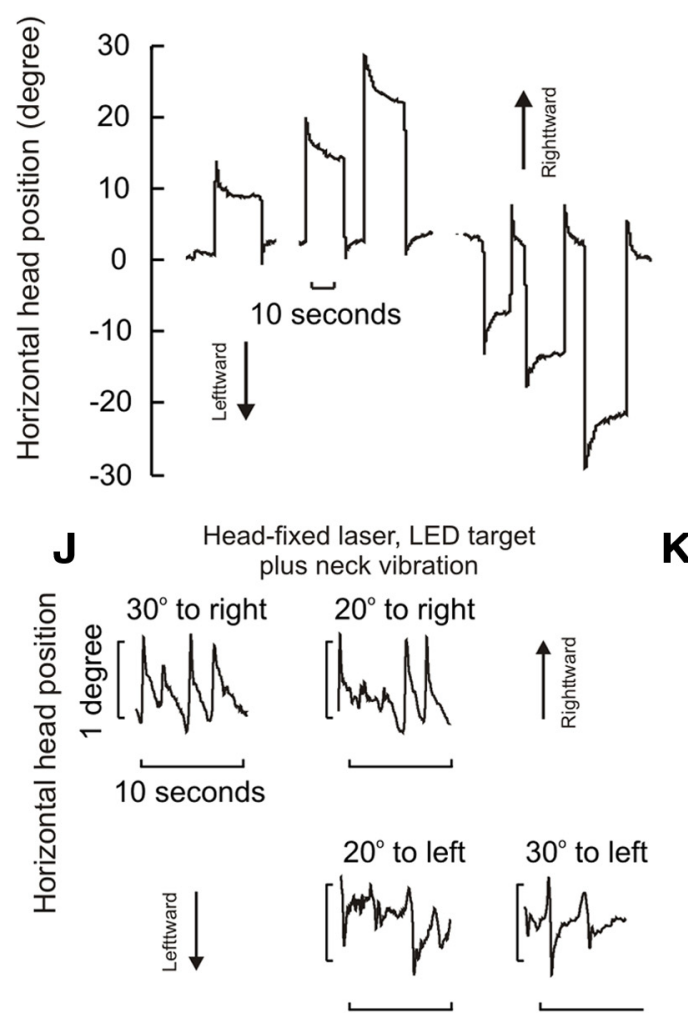

B Head-fixed laser plus LED target
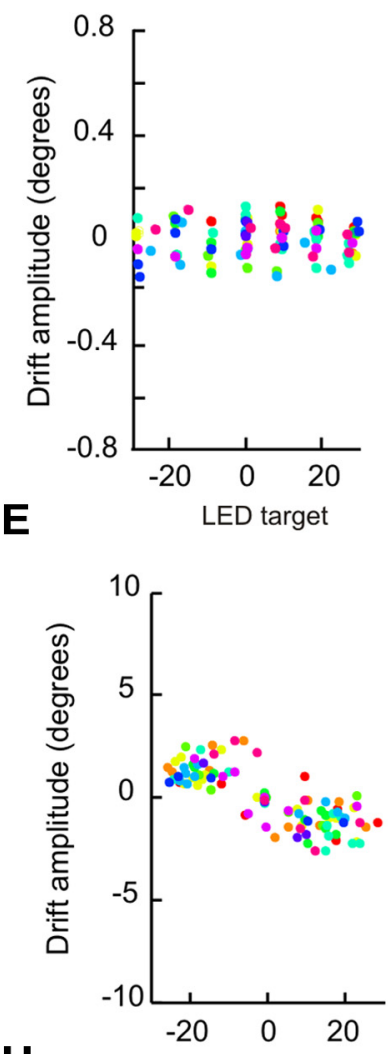

H

LED target plus neck vibration

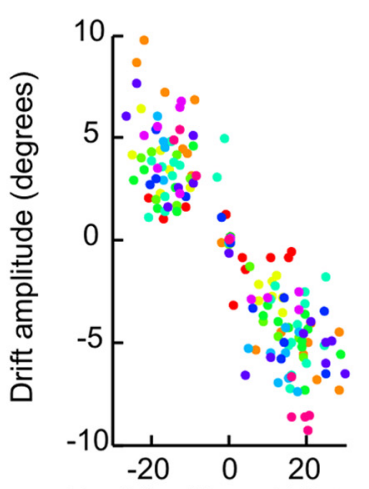

K

Head-fixed laser, LED target plus neck vibration

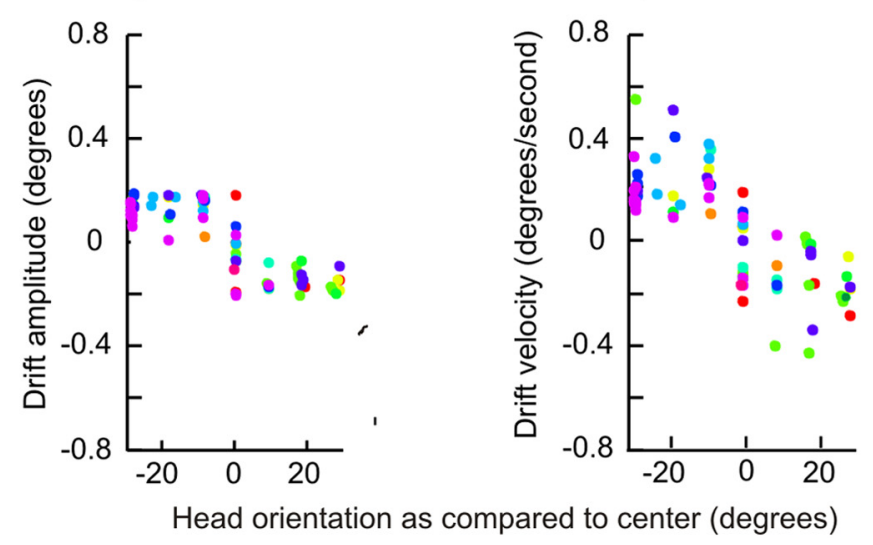

Figure 2. Holding the head on target under different conditions. For the condition with head-fixed laser plus LED target, subjects aligned the projection of laser fixed to the top of the head with a visible LED target $(\boldsymbol{A}-\boldsymbol{C})$. For the condition with LED target only, subjects turned the head and held it on target without the head-fixed laser (D-F). For the condition with vibration and LED target, gentle vibration was applied to the dorsal spinous processes of the neck to affect muscles on both sides $(\mathbf{G}-\mathbf{I})$. The last condition combined the head laser, neck vibration, (Figure legend continues.) 
Table 1. Comparison of horizontal head drifts under different conditions in healthy individuals

\begin{tabular}{|c|c|c|c|c|}
\hline \multirow[b]{2}{*}{ Experimental condition } & \multicolumn{3}{|c|}{ Gaze-evoked horizontal drifts } & \multirow{2}{*}{$\frac{\text { Rebound drifts }}{\text { Velocity slope }\left(s^{-1}\right)}$} \\
\hline & Amplitude slope & Velocity slope $\left(s^{-1}\right)$ & Null position (degrees) & \\
\hline LED target plus laser & $-0.0001 \pm 0.0001$ & $0.0003 \pm 0.001$ & N/A & $0.001 \pm 0.002$ \\
\hline LED target only & $-0.03 \pm 0.01$ & $-0.008 \pm 0.003$ & $0.001 \pm 0.09$ & $0.08 \pm 0.01$ \\
\hline LED target and neck vibration & $-0.22 \pm 0.02$ & $-0.015 \pm 0.003$ & $-0.130 \pm 0.16$ & $0.12 \pm 0.2$ \\
\hline LED target, laser, and neck vibration & $-0.02 \pm 0.008$ & $-0.010 \pm 0.002$ & $0.02 \pm 0.1$ & $0.1 \pm 0.02$ \\
\hline
\end{tabular}

Results for each of the four conditions and four measured variables were compared separately by $t$ test. There were no significant differences among the null positions for any of the conditions. The slopes of amplitudes were significantly different among all conditions $(p<0.001)$, except for conditions of LED target only versus LED target plus laser and neck vibration $(p<0.5)$. The slopes of velocities were also significantly different among all conditions ( $p<0.001)$, again except for conditions of LED target only versus laser, LED target and neck vibration $(p<0.5)$.

Table 2. Comparison of slopes of linear relationship of vertical and torsional drift velocities and horizontal head eccentricities under different conditions in healthy individuals

\begin{tabular}{lcc}
\hline Experimental condition & $\begin{array}{l}\text { Vertical velocity } \\
\text { slope }\left(s^{-1}\right)\end{array}$ & $\begin{array}{l}\text { Torsional velocity } \\
\text { slope }\left(s^{-1}\right)\end{array}$ \\
\hline LED target plus laser & $0.0003 \pm 0.002$ & $-0.001 \pm 0.006$ \\
LED target only & $0.0002 \pm 0.0007$ & $0.0006 \pm 0.0001$ \\
LED target and neck vibration & $0.002 \pm 0.003$ & $0.001 \pm 0.001$ \\
LED target, laser, and neck vibration & $-0.003 \pm 0.008$ & $0.008 \pm 0.007$ \\
\hline
\end{tabular}

Data for amplitudes are not shown because they were nil.

the drift has an exponentially decaying waveform. After one time constant the function will have reached $62 \%$ of its final value. The decay time constant was measured using the ratio of horizontal eccentricity of the initial head position and the velocity of the first third of the drift (initial drift velocity). The decay time constant did not depend on the eccentricity of the initial head position. The values of the time constant during all eccentricities were therefore collated for further analysis. The decay time constant of horizontal drifts during the LED target condition was $47.9 \pm$ $25.4 \mathrm{~s}$ (mean $\pm \mathrm{SD}$ ). The time constant decreased significantly to $28.4 \pm 19.7 \mathrm{~s}$ during the LED target plus neck vibration condition ( $t$ test, $p=0.003$, df $=429$ ) (Fig. 3 ). The decay time constants could not be determined in cases where drifts were minimal or absent, for example in the condition where LED and laser were both used, or for head movements along orthogonal (torsion and vertical) directions.

The head drifts with the fourth condition (laser plus vibration and LED target) were accompanied by frequent corrective movements, bringing the head back to target. The velocities of the corrective head movements were significantly larger than the velocities of the drifts (Fig. $4 A, B$ ). Such a pattern led to repetitive cycles with alternating fast and slow head movements resembling jerk nystagmus of the eyes (Figs. $2 J, 4 B$ ). If the rapid head movements are indeed analogous to the rapid movements of eye nystagmus (the quick phases), the velocities of the rapid corrective head movements should have the same dynamic properties of normal head saccades because they presumably reflect voluntary corrections for involuntary head drift. The dynamic properties of saccades are commonly described by a "main sequence," in which peak velocity is compared with the corresponding saccade amplitude. The main sequence relationship of the corrective quick phases of the head movements (Fig. $4 C$, gray points) and the

$\leftarrow$

(Figure legend continued.) and LED target $(\boldsymbol{J}-\boldsymbol{L})$. For actual head position traces, horizontal head positions are plotted along the ordinate and time along the abscissa $(\boldsymbol{A}, \boldsymbol{D}, \boldsymbol{G}, \boldsymbol{J})$. Head drift amplitudes are shown in $\boldsymbol{B}, \boldsymbol{E}, \boldsymbol{H}$, and $\boldsymbol{K}$. Initial head drift velocities are shown in $\boldsymbol{C}, \boldsymbol{F}, \boldsymbol{I}$, and $\boldsymbol{L}$. Drift amplitudes or velocities are plotted along $y$-axis, and eccentric head positions along $x$-axis. Each data point represents one drift movement, while each color depicts one subject. For all panels, positive values of head position indicate rightward head positions, and negative values indicate leftward head positions.

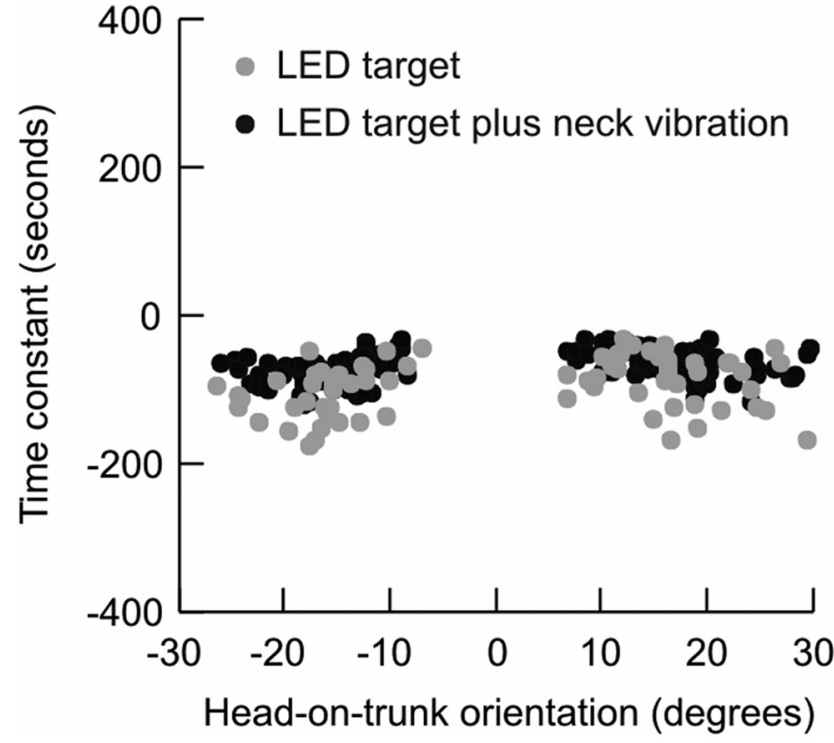

Figure 3. Decay time constants for head drifts according to degree of eccentricity. The amount of eccentricity did not affect the time constants.

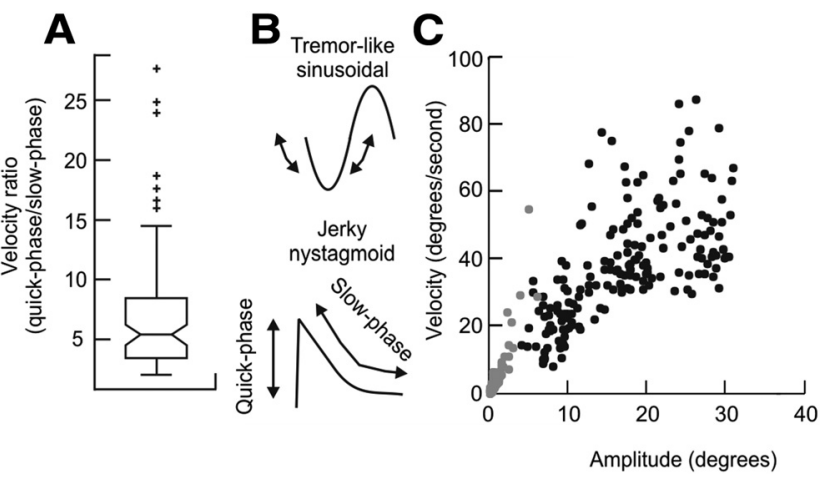

Figure 4. A comparison of the two phases of head movement in normal subjects with a head fixed laser and neck vibration attempting to hold the head toward a specific LED target. $A$ is a box-andwhisker plot summarizing the ratio of fast (quick-phase) and slow (drift) head movements. The horizontal line in the center of notch represents the median ratio, the whiskers represent the range, and symbols represent outliers. $\boldsymbol{B}$ shows the schematic of sinusoidal waveform for typical tremors, compared with the nonsinusoidal waveform for the jerky head movements. $C$ illustrates the mainsequence analysis of corrective head movements (gray) of the quick phases compared with the mainsequence analysis for voluntary head saccades (black). The kinematics of quick phases and visually guided head saccades were compared by fitting each dataset to a power law function between amplitude and peak velocity. The data from both sources revealed no significant differences in this function, although those for the larger jerky head movements were smaller than those of the head saccades.

main sequence for visually guided head saccades (Fig. 4C, black points) were compared quantitatively by fitting the data points during both conditions with a power law function relating amplitude $(A)$ and peak velocity $(V \mathrm{p})$. The power law function 

A Head-fixed laser plus LED target

\section{B \\ LED target}
C LED target plus
neck vibration

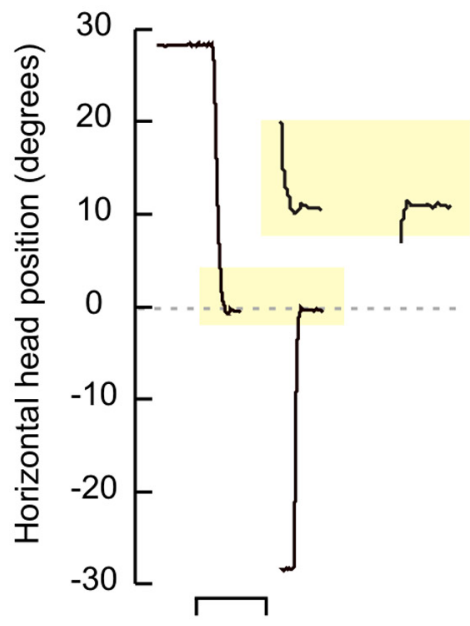

5 seconds

E

Head-fixed laser plus LED target

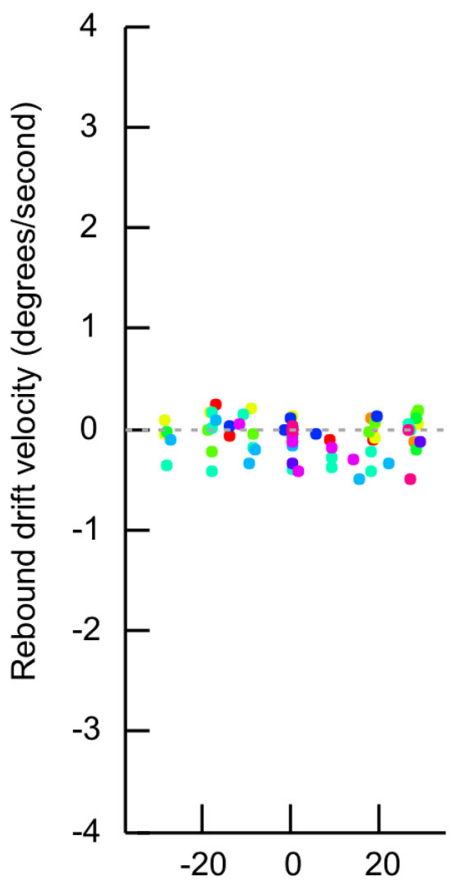

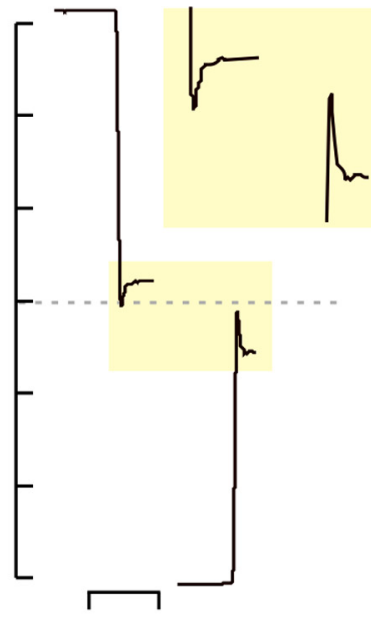

5 seconds

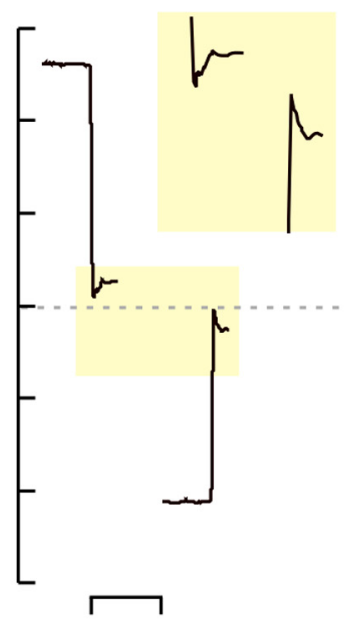

5 seconds
F LED target

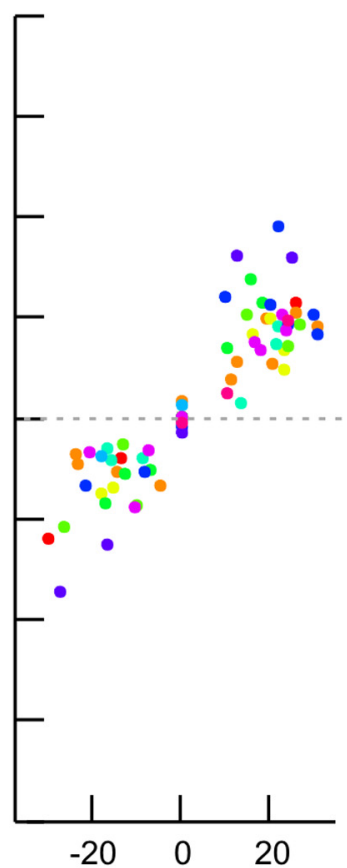

G LED target plus

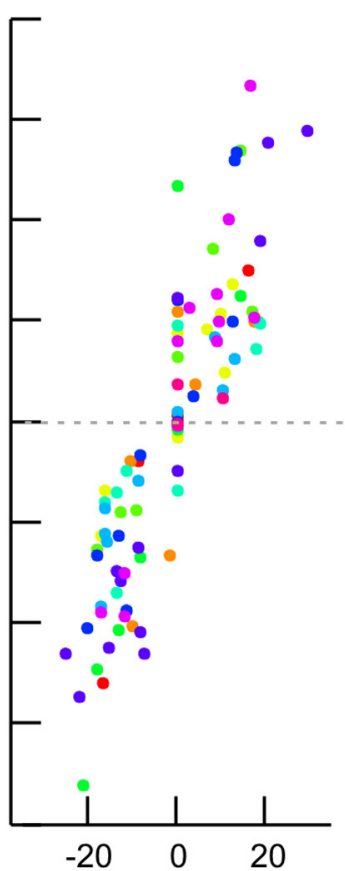

Head-fixed laser
LED target plus
neck vibration

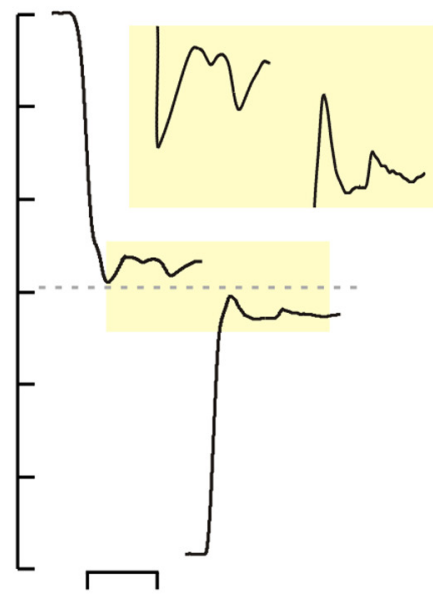

5 seconds

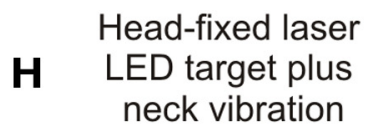

Horizontal head orientation prior to returning to center (degrees)

Figure 5. Rebound head nystagmus. $\boldsymbol{A}-\boldsymbol{D}$ depict the head dynamics for a typical normal subject under each of the four test conditions. $\boldsymbol{A}$ depicts the condition with the head-fixed laser aimed at the LED light; the head was stable during both eccentric positions and after returning to the midline. $\boldsymbol{B}$ shows the condition with LED target but no laser. The addition of neck vibration is shown in $\boldsymbol{C}$, while LED and head-fixed target plus neck vibration is shown in $\boldsymbol{D} . \operatorname{In} \boldsymbol{B}-\boldsymbol{D}$ the rebound drifts were apparent when the head returned to the midline ( $\boldsymbol{B}-\boldsymbol{D}$, highlighted yellow boxes). The drifts were not present in the condition including LED target plus laser, but were in the remaining three experimental paradigms. $\mathbf{E}-\boldsymbol{H}$ objectively summarize all data from all subjects. The velocities for rebound head drifts are plotted on the $y$-axis with head position during prior eccentric head position along the $x$-axis. Each data point represents one rebound drift and each color depicts one subject. The negative values for head orientation depict leftward positions and the negative values for velocities represent leftward drifts. Rebound drifts were always directed opposite those evoked by holding eccentric positions, with positive slopes for all conditions. The data points and positive slope values indicate that leftward rebound drifts were associated with leftward head holding before return to midline, and vice versa.

$\left(V \mathrm{p}=k A^{\mathrm{a}}\right)$ was transformed for a linear regression as $\log (V \mathrm{p})=$ $\mathrm{a}^{\star} \log (A)+\log (k)$, where $a$ was the slope and $\log (k)$ was the intercept of the main sequence in $\log -\log$ coordinates. The slope for quick corrective phases of head movements in the fourth test condition was $0.7 \pm 0.1$, while that for visually guided head saccades was $0.8 \pm 0.5$. The linear fit for visually guided head saccades fell within the $95 \%$ confidence interval of the linear fit of the quick phases of head corrections. Although this comparison 

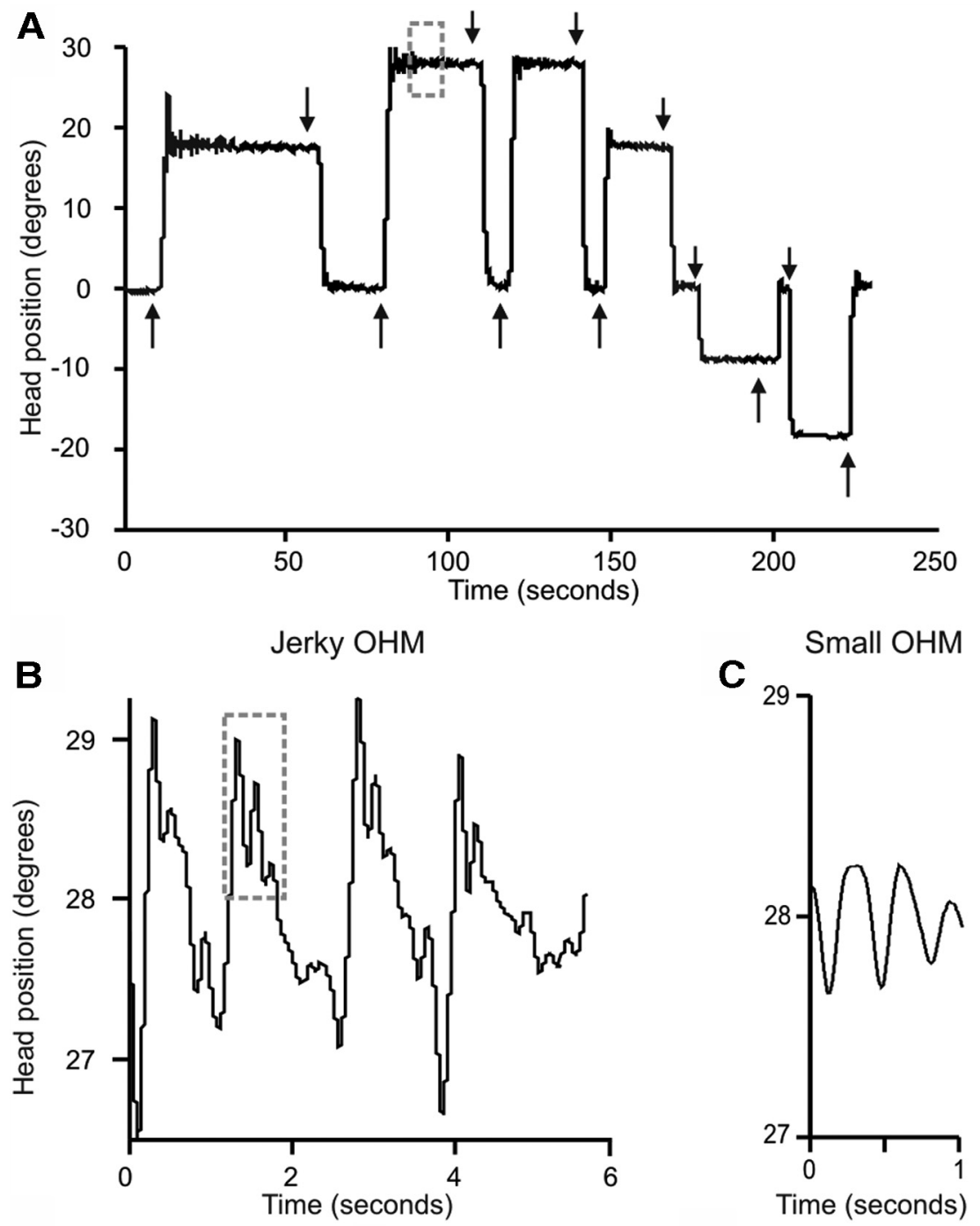
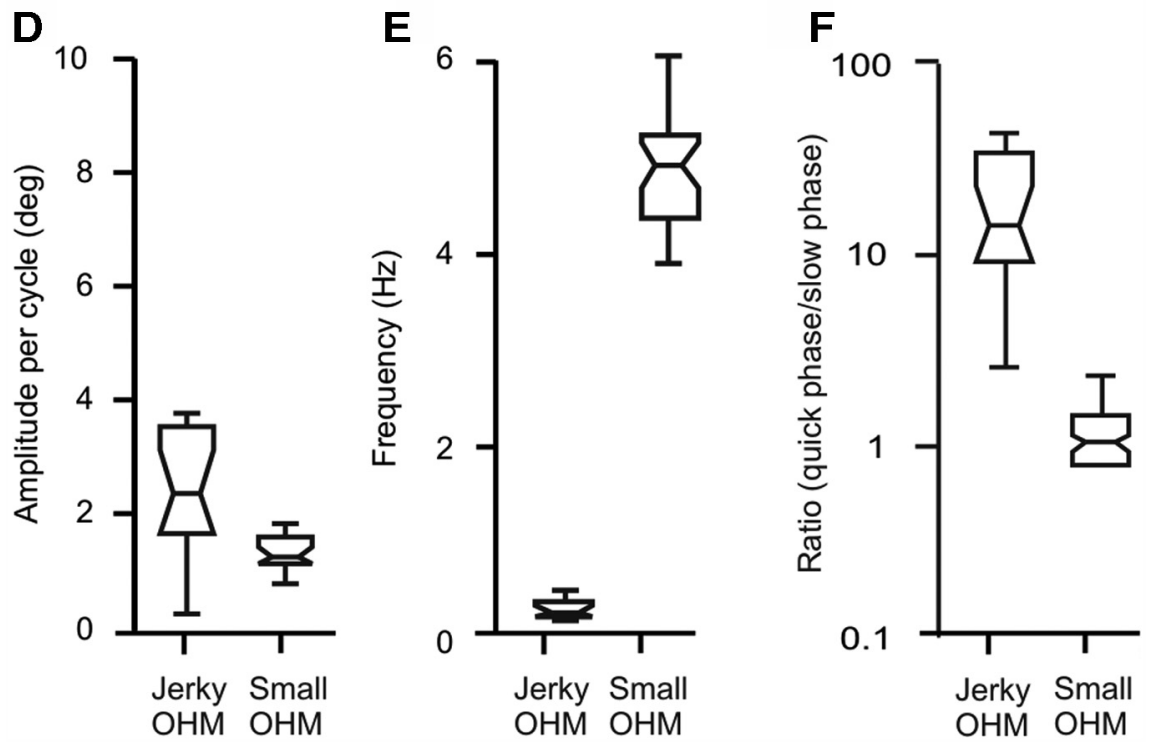

Figure 6. An example of typical head movements in a patient with CD wearing a head-fixed laser and attempting to aim the head at specific LED targets. The head does not remain on target, but demonstrates a recurring cycle of slow drifts away from the target with rapid corrections back to target $(\boldsymbol{A})$. Magnification of the gray box zone in $\boldsymbol{A}$ shows large amplitude $0 \mathrm{HM}$ with a waveform that does not appear sinusoidal $(\boldsymbol{B})$. Further magnification of the trace in $\boldsymbol{B}$ reveals a superimposed smaller $0 \mathrm{HM}$ with a more sinusoidal waveform $(\boldsymbol{C})$. Box-and-whisker plots show that these two different 0 HM have different amplitudes $(\boldsymbol{D})$ and frequencies $(\boldsymbol{E})$. In these plots, the central horizontal line represents the median, the height of the box represents the is limited by the fact that the fast head movements following head drifts were small, the results support the idea that the fast corrective head movements are analogous to the corrective saccades of gazeevoked, jerk nystagmus of the eyes.

Rebound nystagmus is a well documented feature in patients who have gaze-evoked jerk nystagmus of the eyes (Hood et al., 1973). The drifts of rebound nystagmus appear transiently on return of the eyes to the midline position after prolonged eccentric eye holding. These drifts are directed toward the prior eccentric position, and hence are opposite to the slow phases of gazeevoked eye nystagmus. If the head drifts are analogous to jerk of the eyes then rebound head drifts may also occur. In fact, rebound head drifts appeared under all test conditions involving sustained eccentric head holding except the first condition with the head-fixed laser aimed toward visible LEDs (Fig. 5). For all conditions, the rebound drifts were directed toward the prior eccentric position. The rebound drift velocity linearly changed with head eccentricity, and it increased as the head was turned farther away from the central null position. The slope of the linear fit between the rebound drift velocity and head eccentricity during the first condition with the head laser aimed toward the visible LED was $0.001 \pm 0.002 \mathrm{~s}^{-1}$. There was an increase in the slope during the second condition $\left(0.08 \pm 0.01 \mathrm{~s}^{-1}\right)$ when the visual reference of the head position was removed. Addition of neck vibration further increased the slope to $0.12 \pm$ $0.2 \mathrm{~s}^{-1}$ and $0.1 \pm 0.02 \mathrm{~s}^{-1}$ during the third and fourth conditions, respectively. Figure 5 and Table 1 summarize rebound drift velocities and their dependence on the eccentricity of horizontal head position. These results demonstrate a dynamic phenomenon affecting head movement that was predicted by assuming that neural substrate responsible for holding eccentric eye and head positions obey similar mechanisms.

These studies of normal individuals revealed two important phenomena. First, the head drifted centripetally from eccentric positions when either visual feedback

\footnotetext{
$\leftarrow$

spread around the median, while the whiskers represent the range. The first type of $\mathrm{OHM}(\boldsymbol{B})$ has a larger amplitude and lower frequency than the second $\mathrm{OHM}(\boldsymbol{C})$. The median quickphase/slow-phase (in case of sinusoidal oscillations faster to slower movement) ratio for the small OHM was close to 1.0 as expected for a sinusoidal waveform, while that for the larger OHM was significantly higher as expected for a nonsinusoidal waveform $(\boldsymbol{F})$.
} 

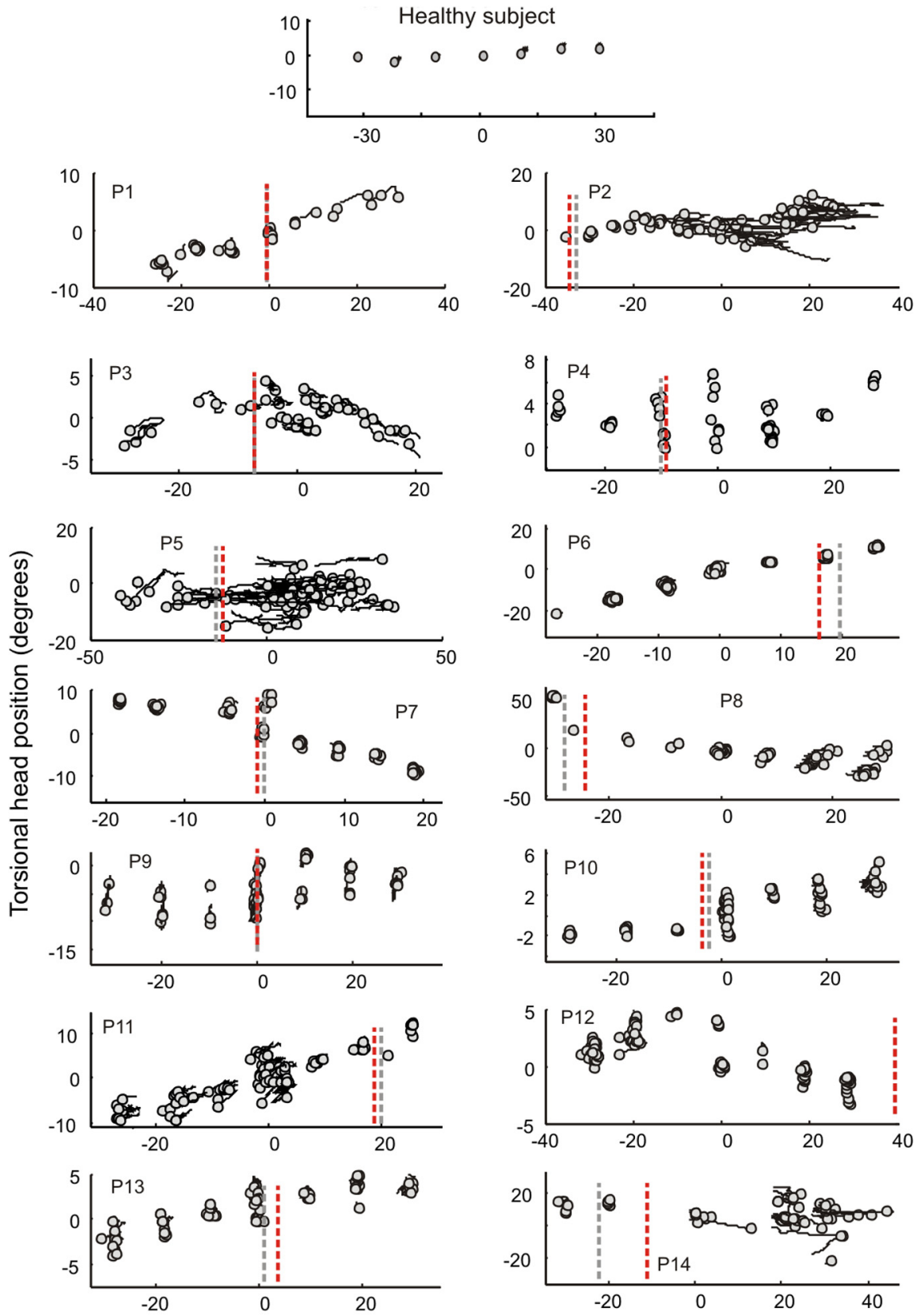

Horizontal head position (degrees)

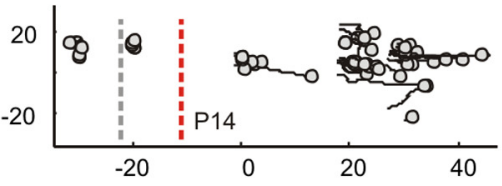

Horizontal head position (degrees)

Figure 7. Head drift in a healthy subject and 14 patients with CD while aiming the head at LED targets with the aid of a head-fixed laser for accuracy. Torsional head positions ( $y$-axis) were plotted against horizontal head position ( $x$-axis). The circles show the initial target position and the lines depict drifts. Lines parallel to the abscissa represent pure horizontal drift and lines parallel to the ordinate pure torsional drift. The lines representing drifts often had an oblique component, indicating a combination of horizontal and torsional drifts. In healthy subjects head drifts were negligible, so the figure shows only circle symbols without lines (top). CD patients exhibited drift along all three axes (panels P1-P14). Gray dashed lines represent the horizontal coordinates of the mathematically derived null while red dashed lines are the horizontal coordinates of the clinical null.

about head position was eliminated or proprioceptive feedback from the neck was distorted. There was a consistent null position close to the straight-ahead position where drifts were minimal or absent. At eccentric positions head drifts always were directed toward the null, and drift amplitudes and velocities were proportional to the degree of head eccentricity. The drifts had a decaying trajectory, but the time constant of decay was independent of desired eccentric position, behavior typical of a neural integrator. After the head returned to the midline following a period during which it was held in an eccentric position, rebound head drifts occurred toward the direction in which the head was turned. These characteristics are consistent with a head-holding mechanism that is inherently leaky, requiring feedback to improve its performance. This result also demonstrates a short-term adaptation to keep the head in an eccentric position as reflected in the transient rebound drift on return to the straightahead position. This phenomenon is analogous to rebound eye nystagmus in patients with, for example, cerebellar dysfunction (Hood et al., 1973; MoralesGarcia et al., 1978; Zee et al., 1980; Zee et al., 1981). Of course, under normal circumstances, visual feedback regarding the position of the head provided by a headfixed laser is not available. As a result, proprioceptive feedback may help to stabilize the position of the head under more natural conditions. Indeed, when proprioceptive feedback was distorted by neck vibration, there was not only an increase in the velocity of head drifts but their kinematic properties also changed as reflected in a decrease in decay time constants. The latter finding suggests that neck proprioception is a critical component in improving the performance of the headholding neural integrator mechanism.

The second important phenomenon was an unusual repetitive movement of the head when proprioception was disrupted and a laser fixed to the head provided visual feedback on the accuracy of head positions. This pattern of head movement, with a slow drift in one direction followed by a rapid corrective movement in the other, resembled gaze-evoked, jerk nystagmus of the eyes. By analogy to eye nystagmus, the slow movement would be the involuntary drift of the head away from the target but, in the case of the head, exacerbated by inadequate or altered proprioceptive feedback from the neck. The rapid corrective movement that brings the head back to target is likely a voluntary movement initiated partly by visual feedback based on the disparity between the positions of the head-fixed laser and the LED target. This repetitive cycle of head movements is similar to the abnormal head movements provoked in monkeys by experimental perturbation of the proposed neural integrator for head control (Klier et al., 2002, 2007; Farshadmanesh et al., 2007, 2008). The repetitive head movements observed in normal subjects also resembled movements seen in patients with $C D$, prompting further exploration of the hypothesis that dysfunction of a neural integrator for head control underlies this disorder (Klier et al., 2002, 2007; Farshadmanesh et al., 2007, 2008).

\section{Abnormal head movements in CD}

Patients with CD typically exhibit two main types of abnormal movements (Chan et al., 1991; Jankovic et al., 1991; Rondot et al., 
1991; Pal et al., 2000). First is a slow involuntary turning or tilting of the head into an abnormal position. Second are oscillatory head movements (OHM) classified clinically as "tremor." Although movements vary among CD patients, they tend to be relatively stereotyped in an individual. Figure 6 shows a representative example of these OHM in the horizontal plane for a patient with $\mathrm{CD}$ attempting to hold the head steadily aimed toward an LED target straight ahead with a head-fixed laser providing visual feedback. Close inspection of the OHM revealed two subtypes as previously described (Ansari and Webster, 1974; Dauer et al., 1998). One subtype had a large amplitude and low frequency with a jerky quality caused by slow movement in one direction with a faster movement in the opposite direction (Fig. 6B,D-F). Superimposed on the jerky OHM was a second subtype of OHM with a small amplitude and high frequency (Fig. 6C-F). Jerky and small OHM also occurred along the vertical and torsional axes (data not shown).

The small OHM were observed only in five patients and had characteristics similar to "essential tremor" including frequency, amplitude, sinusoidal waveform, and regularity (Fig. 6C-F). Tremor commonly occurs in CD (Ansari and Webster, 1974; Chan et al., 1991; Jankovic et al., 1991; Pal et al., 2000) so these findings were not unexpected. The jerky OHM were more characteristic of "dystonic tremor" and were examined in more detail since they occurred in all 14 patients. These jerky OHM had properties suggestive of "head nystagmus," as might be expected from a defect in a neural integrator for head movement. For example, the waveform of the jerky $\mathrm{OHM}$ is comprised of two different movements with differing velocities, similar to the slow and fast phases of jerk nystagmus of the eyes (Fig. 6B,F). We therefore further examined the jerky $\mathrm{OHM}$ in $\mathrm{CD}$ by testing several predictions based on the neural integrator hypothesis.

The first prediction relates to the concept of a null position for a neural integrator, where drifts are minimal or absent. Patients with CD have a favored head position defined as the clinical null (Jankovic, 2007). Asking each patient to let the head find its most comfortable position without resistance identified the null position. The clinical null position for horizontal movements among these patients was straight ahead for five but eccentric for nine, sometimes by $>20$ degrees (Fig. 7 , red lines).

Patients next were asked to direct the head toward LED targets in a dark room with a laser attached to the head as a visual cue for accuracy. Unlike normal individuals, who were able to maintain a stable head position, all CD patients had drifts of the head. In some they were large enough to be visible on clinical examination (P2, P5, P14) and in others they could be detected only with the head coil tracking system (Fig. 7). The mathematical null position, predicted by the neural integrator hypothesis, was determined by calculating the head position where drift velocity was $(C, D)$.
Patient 10 eaky integrator (30 right)

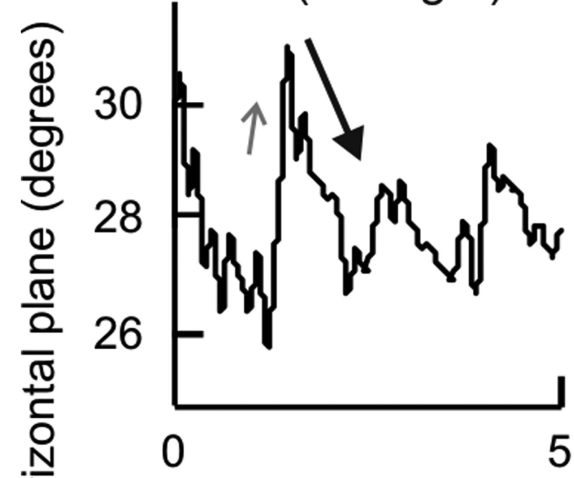

5

Null position (18 $18^{\circ}$ to left)

Figure 8. Two different types of head drifts seen in patients with $C D$. These types are based on the direction of the head drift in relation to the null position. In both cases horizontal head position is plotted on the $y$-axis and time is plotted on the $x$-axis, and the for the drifts by bringing the head back to the desired orientation. In two patients, head drifts moved the head away from the null

smallest for each patient (Fig. 7, gray lines). The mathematically derived nulls were highly correlated with the empirically determined clinical nulls (slope $=0.9 ; r^{2}=0.98$ ).

Another prediction of the head integrator hypothesis for CD is based on the relationship between the starting position relative to the null and the initial drift velocity of the head. For jerk nystagmus of the eyes, centripetal drift velocity increases with increasing distance of the eyes from the null. The horizontal head position and the initial horizontal head drift velocity for the jerky OHM revealed a similar relationship; initial drift velocity decreased as the desired head position approached the null (Figs. $8,9)$. To test further the neural integrator hypothesis, we measured the slope of the relationship between horizontal eccentricity and horizontal drift velocity, which gives one a measure of the fidelity of integration. The influence of horizontal eccentricity on the horizontal drift velocity was quantified by measuring the slope of their linear relationship (Table 3 ). The higher the value of the slope, the more imperfect is the integration.

Another prediction relating to the null position is that the direction of head drift should reverse when the head is moved past the null position. In most patients the head drifted toward the null, these patients had rightward drift after the head was moved to the left of the null, and leftward drift after the head was 

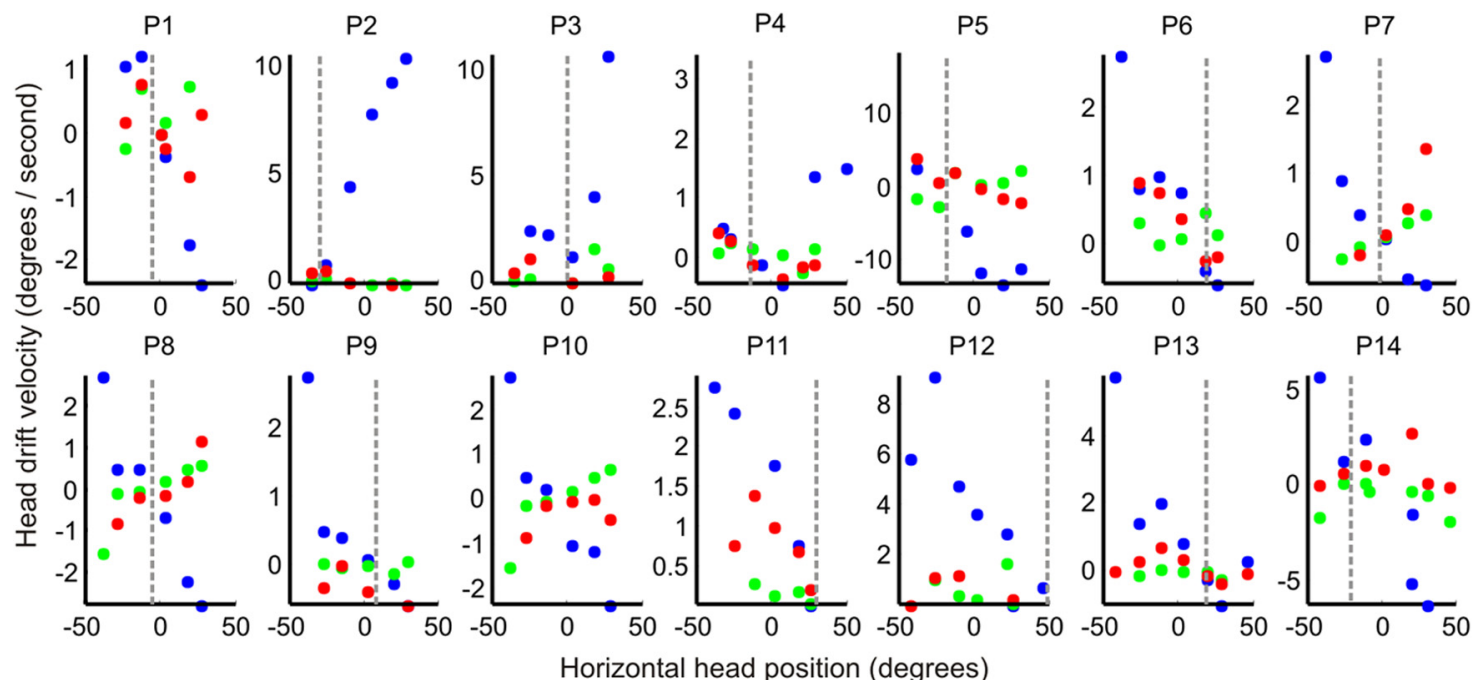

Figure 9. Relationship between drift velocity and null positions in CD. Blue data points depict horizontal drift velocity. Horizontal drift velocity in CD is minimal at the null position, and increases with distance from the null. There is a reversal in the drift direction as the head orientation shifts from the right of the null to the left. This phenomenon is reflected in the change in the sign of the drift velocity. Red and green data points depict relationships between torsional and vertical drift velocities with horizontal head position. Axes were customized for each patient to most clearly demonstrate the size and direction of drifts.

Table 3. Slopes of linear fit relating horizontal, vertical, and torsional head velocity with eccentric horizontal head orientation in patients with CD

\begin{tabular}{llll}
\hline & \multicolumn{2}{l}{ Velocity slope $\left(\mathrm{s}^{-1}\right)$} & \\
\cline { 2 - 4 } Patient number & Horizontal & Vertical & Torsional \\
\hline 1 & -0.07 & 0.03 & -0.01 \\
2 & 0.19 & 0.00 & -0.03 \\
3 & 0.12 & 0.02 & -0.02 \\
4 & 0.03 & 0.00 & -0.01 \\
5 & -0.38 & 0.05 & -0.08 \\
6 & -0.04 & 0.02 & -0.05 \\
7 & -0.04 & 0.02 & -0.01 \\
8 & -0.08 & 0.03 & -0.02 \\
9 & -0.04 & 0.01 & -0.05 \\
10 & -0.06 & 0.03 & -0.04 \\
11 & -0.04 & 0.02 & -0.04 \\
12 & -0.07 & 0.00 & -0.02 \\
13 & -0.04 & 0.00 & -0.01 \\
14 & -0.08 & 0.00 & 0.00 \\
\hline
\end{tabular}

moved to the right of the null (Figs. $8 A, B, 9$ ). Negative values of slopes of horizontal drifts suggest direction of drift toward the null (Table 3). However, in two patients (P2, P3) head drifts were clearly away from the null (Figs. $8 C, D, 9$ ); in these cases the value of slope was positive. Such behavior suggests an unstable integrator, rather than a leaky one (Zee et al., 1980; Zee et al., 1981). For some patients the null position appeared to be at a far eccentric position, where reversal of drift could not be measured for biomechanical reasons (e.g., P2, P5, P6, P11, P12).

We then assessed whether vertical and torsional drifts also were modulated by changes in horizontal head position. Green and red colored symbols in Figure 9 depict the dependence of vertical and torsional drift velocity on horizontal head position. This dependence was further quantified by measuring the slope of corresponding linear fit (Table 3). In most instances horizontal drift velocity depended more strongly on horizontal head eccentricity than did vertical and torsional drifts. This relationship is evident from the higher values of the slopes representing horizontal drifts compared with vertical and torsional drifts (Table 3, Fig. 9).

We measured the decay time constant of the horizontal drifts to determine its relationship with eccentricity of horizontal head position (Fig. 10). Unlike with neck vibration in healthy subjects, the decay time constant in CD patients varied with horizontal head position. A single linear neural integrator cannot explain this behavior. Our patients (Table 4), similar to other CD patients (Chan et al., 1991; Jankovic et al., 1991; Rondot et al., 1991; Gabriel et al., 2004), had head movements along multiple axes. Therefore, it is possible that normal synergistic and antagonistic muscles have an altered relationship with one another due to the disorder or secondary compensations, such that drift velocities and time constants vary in a nonlinear fashion.

In the case of gaze-evoked eye nystagmus due to dysfunction of the neural integrator, removal of visual feedback results in increased drift amplitudes and reduced frequency of corrective quick phases (Zee et al., 1976). Consistent with the head neural integrator hypothesis, removing visual feedback by turning off the head-fixed laser in CD patients also increased the amplitude of the drift, with a decrease in the frequency of corrections after each drift. Figure $11 A$ depicts larger head excursions during the condition with LED target alone compared with the condition in which visual feedback about head position was present from the head-fixed laser. Figure $11 B$ depicts more frequent corrective saccades in the presence of visual feedback. This phenomenon also is analogous to jerk nystagmus of the eyes that is secondary to the dysfunction of the neural integrator (Zee et al., 1976).

The dynamic properties of the quick phases of jerk nystagmus of the eyes resemble those of normal visually guided eye saccades. Therefore, another prediction of the hypothesis that jerky OHM are analogous to gaze-evoked eye nystagmus is that the fast head movements should have dynamic properties of head saccades. The peak velocities of the rapid phases of the jerky OHM were plotted against their amplitudes. The data points overlap those from visually guided head saccades in the CD patients (Fig. 11C), suggesting a comparable main-sequence relationship between peak velocity and amplitudes. The rapid head movements were always corrective. When drifts were toward the null, the rapid corrective head movements were directed toward the desired head position and hence directed away from the null. In instances (e.g., P2 and P3) when drifts were away from the null, corrective 


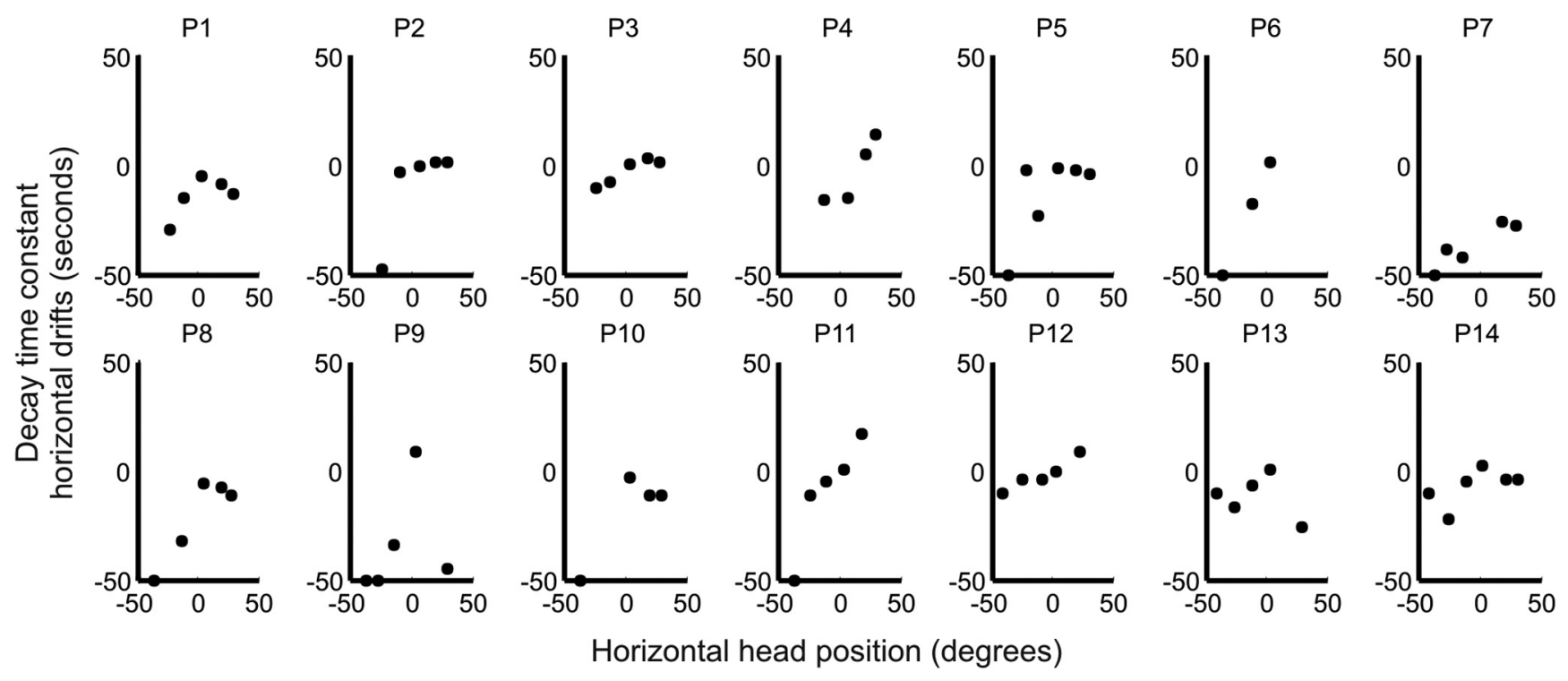

Figure 10. Relationship of horizontal decay time constant and eccentric head position during LED targeted paradigm (without visual feedback). The values of decay time constant are plotted along ordinate while horizontal head position is plotted on abscissa.

Table 4. Demographics and clinical presentation of CD patients

\begin{tabular}{ccccclll}
\hline & \multicolumn{1}{c}{$\begin{array}{l}\text { Age } \\
\text { Patient }\end{array}$} & $\begin{array}{l}\text { Duration of } \\
\text { (yrs) }\end{array}$ & Sex & $\begin{array}{l}\text { Cllness (yrs) } \\
\text { ilinically } \\
\text { apparent }\end{array}$ & $\begin{array}{l}\text { Response to } \\
\text { OHM? } \\
\text { BTX }\end{array}$ & $\begin{array}{l}\text { Duration since } \\
\text { BTX (months) }\end{array}$ \\
\hline 1 & 69 & F & 29 & LC-L & Yes & Good & 3 \\
2 & 48 & F & 12 & TC-L, RC & No & Moderate & 3 \\
3 & 87 & F & 25 & LC-R & Yes & Poor & 3.5 \\
4 & 69 & F & 41 & LC-L & No & Good & 3 \\
5 & 58 & F & 2 & TC-L, AC & No & Good & 3 \\
6 & 74 & F & 12 & LC-R, TC-R & Yes & Moderate & 3 \\
7 & 49 & F & 7 & TC-L, LC-L & No & Good & 3 \\
8 & 57 & F & 12 & TC-L & Yes & Good & 3 \\
9 & 40 & M & 9 & LC-R, TC-L, RC & No & Good & 3 \\
10 & 61 & F & 10 & AC, LC-R & No & Good & 3 \\
11 & 61 & F & 4 & TC-R & No & Moderate & 3 \\
12 & 69 & F & 23 & LC-R & No & Good & 3 \\
13 & 59 & F & 19 & TC-L, LC-R & Yes & Moderate & 3 \\
14 & 48 & F & 9 & LC-R, TC-L & No & Good & 3 \\
\hline
\end{tabular}

BTX, Botulinum toxin; R, Right; L, Left, $T C$, torticollis, AC, anterocollis, LC, laterocollis, RC, retrocollis; yrs, years.

head movements were again directed toward the desired head position, but now were directed toward the null.

\section{Discussion}

Gaze control requires coordinated movements of the eyes and head. Although the neural mechanisms controlling the head are not well understood, prior research in animals has suggested an important role for neural integrators. The current results support the idea of a neural integrator for head movements in humans and explain some of the head movements in patients with CD.

\section{Ocular versus head neural integrators}

The neural integrators for the eyes and head are analogous in that both appear inherently leaky and rely on feedback mechanisms to improve function. Most healthy subjects show subtle end-gaze nystagmus in the dark, a phenomenon attributed to an imperfect ocular integrator and its reliance on visual feedback (Jürgens et al., 1981; Pastor et al., 1994; Abadi and Scallan, 2001; Leigh and Zee, 2006). Patients with cerebellar disease and monkeys with lesions of the cerebellum show enhanced gaze-evoked nystagmus
(Zee et al., 1980, 1981). Here, nystagmus is attributable to abnormalities in an internal feedback loop involving the cerebellum and the ocular integrator. Our results show that the head neural integrator also is imperfect, with drifts away from a target when sensory feedback is disrupted. Visual feedback can improve the function of the head integrator, since head drifts were absent when there was visual feedback from a laser (Fig. 2). These results are consistent with prior studies regarding visual feedback for head control (Guitton et al., 1986). However, under natural circumstances, when a laser is not available, the head integrator cannot rely on visual feedback because eye movements can compensate for head movements.

\section{A role for proprioception in the head integrator}

Unlike the eyes, proprioception from neck muscles appears to have an important influence on the head integrator. In normal subjects, head drifts were most prominent when proprioception was disrupted by vibration (Fig. 2). These results are consistent with prior studies showing the importance of proprioceptive feedback for head control (Smetanin et al., 1993; Anastasopoulos et al., 1998; Bove et al., 2004, 2007; Malmström et al., 2009). There are several reasons the head integrator may depend on proprioception. First, in the case of eye movements, retinal error signals can contribute to a precise estimate of the position of the eye in space. Under natural conditions a similar mechanism does not exist for the head so proprioceptive feedback may be more important. Second, head movements are controlled by many neck muscles that are recruited to different degrees depending upon the orientation of the head on the torso, any given muscle can be activated in more than one plane, and the head is subject to segmental stretch reflexes (Collins and Barnes, 1999; Buford et al., 2002; Gabriel et al., 2004). In contrast, eye movements are constrained to rotations around relatively fixed axes, the inertia of the globe is small, the eye muscles work against an unchanging load, and there are no segmental stretch reflexes. Hence there is less need for proprioceptive feedback to advise the brain where the eye is in the orbit and the brain can rely more confidently on efference copy signals of ocular position. These differences between the head and eyes may explain why sensory feedback from muscle proprioception is more important for the head than the 

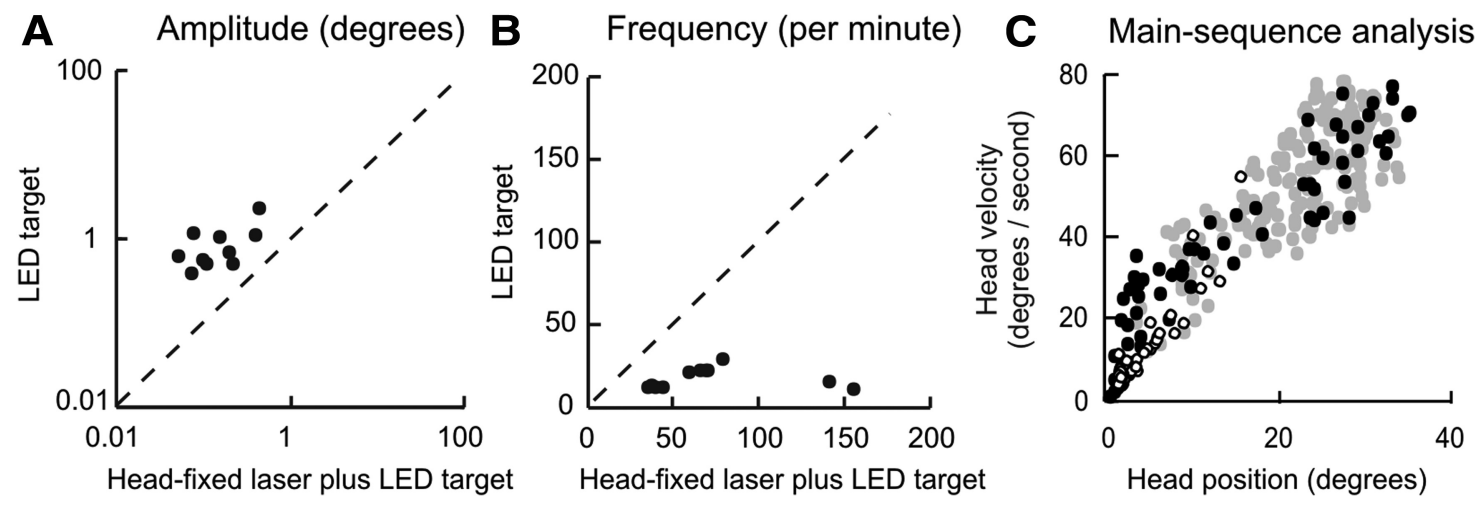

Figure 11. Characteristics of head drifts among CD patients attempting to aim the head at an LED target with or without a head-fixed laser. The amplitudes $(\boldsymbol{A})$ and the frequencies $(\boldsymbol{B})$ of cycles without the head-fixed laser are plotted on the $y$-axis while those with the head-fixed laser are plotted on the $x$-axis. Each data point represents one patient. Dashed line is an equality line. All data points depicting amplitude fell above the equality line, indicating significantly larger drift amplitudes without the laser (paired $t$ test, $p<0.01$ ). Data points representing frequency fell below the equality line, demonstrating a significantly lower frequency without the laser (paired $t$ test; $p<0.05$ ). The relationship between head amplitude and velocity of head movements is shown in $C$. Black symbols show the condition without the laser while open symbols show the condition with the laser. Visually guided head saccades from the same patients are shown in gray. The data from both sources overlapped suggesting similar kinematic properties.

eyes. Still unknown is the nature of the proprioceptive feedback; either negative velocity feedback or positive position feedback are feasible. The viscoelastic properties of the neck and heavy inertia of the head could result in the dampening of dynamics in the neck plant itself, which might mimic the action of a central neural integrator (Peng et al., 1996). Disruption of proprioceptive feedback to such a head plant might cause a similar pattern of drifts. Thus, our analyses do not exclude the role of local peripheral feedback in producing a similar pattern of behavior to a more central neural integrator.

\section{Relevance for understanding abnormal head movements}

Some of the abnormal head movements in patients with CD, such as the jerky OHM, can be predicted by defects in neural integration of head movements. Although the jerky OHM correspond to clinical definitions of dystonic tremor, these definitions have varied over the years, and there is broad recognition that the features of dystonic tremor are not like other tremors (Fahn, 1984; Deuschl et al., 1998; Schiebler et al., 2011). Specifically, tremor is defined as a regular, rhythmic, and sinusoidal oscillation, yet the jerky OHM of CD are neither regular nor sinusoidal. Our analyses of the jerky OHM revealed characteristics that resemble gazeevoked eye nystagmus, a defect predicted to result from impaired feedback to the neural integrator. The features include: (1) a slow drift of the head followed by a rapid corrective movement; (2) a null position where drifts are attenuated; (3) a direction of drift toward or away from the null position depending on whether the integrator is leaky or unstable; (4) a drift velocity that depends on the distance between the desired position and null; and (5) quick phases that have a velocity-amplitude relationship similar to head saccades. In view of these findings, the term head nystagmus may be more appropriate than dystonic tremor for these jerky OHM.

The proposal that jerky OHM in CD are a form of head nystagmus is consistent with recent concepts of the pathogenesis of CD. Studies in animals have suggested that a circuit involving the interstitial nucleus of Cajal (INC) and the nucleus of Darkschewitsch serves as a neural integrator for holding the head steady (Hassler and Hess, 1954; Malouin and Bédard, 1982; Klier et al., 2002; Farshadmanesh et al., 2007; Klier et al., 2007). Experimental perturbations of these regions cause abnormal head postures along with OHM similar to those seen in CD. Unilateral inactivation of this region results in contralateral head tilt while stim- ulation results in ipsilateral tilt. In humans, direct electrical stimulation of this region causes excessive neck muscle activity with head tilt, and surgical lesions improve head postures in CD (Sano et al., 1970, 1972; Hassler et al., 1981; Vasin et al., 1985). Together, these observations suggest that the INC and nearby regions play a role in controlling head position.

Proposals regarding the INC as a neural integrator for head position do not require dysfunction in $\mathrm{CD}$ to be intrinsic to this region (Klier et al., 2002). By analogy to jerk nystagmus of the eyes, defects in the head neural integrator may also result from abnormal feedback. Anatomical studies have shown that the INC receives inputs from the cerebellum, substantia nigra, vestibular nuclei, and neck muscle proprioceptors (Fukushima, 1987). Disruption of these inputs may explain previously reported associations between CD and lesions of the cerebellum, basal ganglia, or their outflow pathways (LeDoux and Brady, 2003; Neychev et al., 2011). Disruption of inputs from the vestibular nuclei may reflect the subtle vestibular abnormalities reported in CD (Münchau and Bronstein, 2001; Münchau et al., 2001). Finally, several studies suggest that the pathogenesis of CD includes abnormal proprioception from neck muscles (Lekhel et al., 1997; Anastasopoulos et al., 1998; Karnath et al., 2000; Bove et al., 2004), which also projects to the interstitial nucleus of Cajal. Thus, the concept of dysfunction of a neural integrator for head position involving the INC and nearby regions accommodates results from many apparently unrelated prior studies of $\mathrm{CD}$, and provides an experimental model for future studies.

The different ways in which the neural integrator can malfunction may be reflected in different clinical manifestations. For example in typical gaze-evoked eye nystagmus caused by suboptimal feedback correction to an inherently leaky integrator, the eyes drift centripetally, away from eccentric targets and toward the null position. Five CD patients showed head drifts toward the null, consistent with a leaky head neural integrator. Less commonly, an unstable integrator may result from excessively large feedback, leading to the eyes drift centrifugally, away from the null position (Zee et al., 1980; Zee et al., 1981). Head movements in two of our CD patients showed this pattern. Finally, eye nystagmus may exhibit an eccentric null position, due to an external bias in afferent input or asymmetric function of the integrator on both sides of the brain, called Brun's nystagmus (Nedzelski, 1983). In our study eight CD patients had eccentric nulls. These 
results imply that $\mathrm{CD}$ may result from different types of defects influencing the neural integrator.

\section{Conclusions}

Our results are compatible with a neural integrator for head position in the human brain, analogous to the neural integrator for eye position. Like the ocular motor integrator, the head integrator is inherently imperfect, requiring sensory feedback for error correction. By manipulating proprioceptive inputs, an abnormal movement resembling dystonic head tremor can be induced in normal subjects. The abnormal head postures and dystonic tremor shown by patients with CD have characteristics that are consistent with the consequences of impairment in a neural integrator for head movements. The current studies therefore provide valuable validation of prior animal studies suggesting fundamental similarities between ocular motor and cephalomotor control, and they point to a conceptual framework for CD that departs considerably from traditional clinical views.

\section{References}

Abadi RV, Scallan CJ (2001) Ocular oscillations on eccentric gaze. Vision Res 41:2895-2907. CrossRef Medline

Anastasopoulos D, Nasios G, Psilas K, Mergner T, Maurer C, Lücking CH (1998) What is straight ahead to a patient with torticollis? Brain 121:91101. CrossRef Medline

Ansari KA, Webster DD (1974) Quantitative measurements in spasmodic torticollis. Description of a method and results of measurement. Dis Nerv Syst 35:44-47. Medline

Bergamin O, Zee DS, Roberts DC, Landau K, Lasker AG, Straumann D (2001) Three-dimensional Hess screen test with binocular dual search coils in a three-field magnetic system. Invest Ophthalmol Vis Sci 42:660667. Medline

Bove M, Brichetto G, Abbruzzese G, Marchese R, Schieppati M (2004) Neck proprioception and spatial orientation in cervical dystonia. Brain 127: 2764-2778. CrossRef Medline

Bove M, Brichetto G, Abbruzzese G, Marchese R, Schieppati M (2007) Postural responses to continuous unilateral neck muscle vibration in standing patients with cervical dystonia. Mov Disord 22:498-503. CrossRef Medline

Buford JA, Yoder SM, Heiss DG, Chidley JV (2002) Actions of the scalene muscles for rotation of the cervical spine in macaque and human. J Orthop Sports Phys Ther 32:488-496. Medline

Burke D, Hagbarth KE, Löfstedt L, Wallin BG (1976) The responses of human muscle spindle endings to vibration of noncontracting muscles. J Physiol 261:673-693. Medline

Cannon SC, Robinson DA (1987) Loss of the neural integrator of the oculomotor system from brain stem lesions in monkey. J Neurophysiol 57: 1383-1409. Medline

Ceylan M, Henriques DY, Tweed DB, Crawford JD (2000) Task-dependent constraints in motor control: pinhole goggles make the head move like an eye. J Neurosci 20:2719-2730. Medline

Chan J, Brin MF, Fahn S (1991) Idiopathic cervical dystonia: clinical characteristics. Mov Disord 6:119-126. CrossRef Medline

Cheron G, Godaux E (1987) Disabling of the oculomotor neural integrator by kainic acid injections in the prepositus-vestibular complex of the cat. J Physiol 394:267-290. Medline

Collins CJ, Barnes GR (1999) Independent control of head and gaze movements during head-free pursuit in humans. J Physiol 515:299-314. CrossRef Medline

Corneil BD, Olivier E, Munoz DP (2002) Neck muscle responses to stimulation of monkey superior colliculus. II. Gaze shift initiation and volitional head movements. J Neurophysiol 88:2000-2018. Medline

Crawford JD, Cadera W, Vilis T (1991) Generation of torsional and vertical eye position signals by the interstitial nucleus of Cajal. Science 252:15511553. CrossRef Medline

Dauer WT, Burke RE, Greene P, Fahn S (1998) Current concepts on the clinical features, aetiology and management of idiopathic cervical dystonia. Brain 121:547-560. CrossRef Medline

Deuschl G, Bain P, Brin M (1998) Consensus statement of the movement disorder society on tremor. Mov Disord 13 [Suppl 3]:2-23. Medline
Fahn S (1984) The varied clinical expressions of dystonia. Neurol Clin 2:541-554. Medline

Farshadmanesh F, Klier EM, Chang P, Wang H, Crawford JD (2007) Threedimensional eye-head coordination after injection of muscimol into the interstitial nucleus of Cajal (INC). J Neurophysiol 97:2322-2338. CrossRef Medline

Farshadmanesh F, Chang P, Wang H, Yan X, Corneil BD, Crawford JD (2008) Neck muscle synergies during stimulation and inactivation of the interstitial nucleus of Cajal (INC). J Neurophysiol 100:1677-1685. CrossRef Medline

Freedman EG, Sparks DL (1997a) Eye-head coordination during headunrestrained gaze shifts in rhesus monkeys. J Neurophysiol 77:23282348. Medline

Freedman EG, Sparks DL (1997b) Activity of cells in the deeper layers of the superior colliculus of the rhesus monkey: evidence for a gaze displacement command. J Neurophysiol 78:1669-1690. Medline

Fukushima K (1987) The interstitial nucleus of Cajal and its role in the control of movements of the head and eyes. Prog Neurobiol 29:107-192. CrossRef Medline

Gabriel DA, Matsumoto JY, Davis DH, Currier BL, An KN (2004) Multidirectional neck strength and electromyographic activity for normal controls. Clin Biomech 19:653-658. CrossRef

Gandhi NJ, Sparks DL (2007) Dissociation of eye and head components of gaze shifts by stimulation of the omnipause neuron region. J Neurophysiol 98:360-373. CrossRef Medline

Gandhi NJ, Barton EJ, Sparks DL (2008) Coordination of eye and head components of movements evoked by stimulation of the paramedian pontine reticular formation. Exp Brain Res 189:35-47. CrossRef Medline

Gauthier GM, Nommay D, Vercher JL (1990a) Ocular muscle proprioception and visual localization of targets in man. Brain 113:1857-1871. CrossRef Medline

Gauthier GM, Nommay D, Vercher JL (1990b) The role of ocular muscle proprioception in visual localization of targets. Science 249:58-61. CrossRef Medline

Guitton D, Kearney RE, Wereley N, Peterson BW (1986) Visual, vestibular and voluntary contributions to human head stabilization. Exp Brain Res 64:59-69. Medline

Hassler R, Hess WR (1954) Experimentelle anatomische Befunde uber die Drehbewegungen und ihre nervosen Apparate. Arch Psychiatr Nervenkr Z Gesamte Neurol Psychiatr 192:488-526. Medline

Hassler R, Vasilescu C, Dieckmann G (1981) Electromyographic activity of neck muscles in patients affected by retrocollis under the influence of stimulation and coagulation of the prestitial nucleus of the midbrain. Appl Neurophysiol 44:291-301. Medline

Hood JD, Kayan A, Leech J (1973) Rebound nystagmus. Brain 96:507-526. CrossRef Medline

Jankovic J (2007) Dystonic disorders. In: Parkinson's disease and movement disorders, Ed 5 (Jankovic J, Tolosa E, eds), pp 319-347. Philadelphia: Lippincott, Williams and Wilkins.

Jankovic J, Leder S, Warner D, Schwartz K (1991) Cervical dystonia: clinical findings and associated movement disorders. Neurology 41:1088-1091. CrossRef Medline

Jürgens R, Becker W, Kornhuber HH (1981) Natural and drug-induced variations of velocity and duration of human saccadic eye movements: evidence for a control of the neural pulse generator by local feedback. Biol Cybern 39:87-96. CrossRef Medline

Kaji R, Rothwell JC, Katayama M, Ikeda T, Kubori T, Kohara N, Mezaki T, Shibasaki H, Kimura J (1995) Tonic vibration reflex and muscle afferent block in writer's cramp. Ann Neurol 38:155-162. CrossRef Medline

Karnath HO, Konczak J, Dichgans J (2000) Effect of prolonged neck muscle vibration on lateral head tilt in severe spasmodic torticollis. J Neurol Neurosurg Psychiatry 69:658-660. CrossRef Medline

Keshner FA, Peterson BW (1995) Mechanisms controlling human head stabilization. I. Head-neck dynamics during random rotations in the horizontal plane. J Neurophysiol 73:2293-2301. Medline

King WM, Fuchs AF, Magnin M (1981) Vertical eye movement-related responses of neurons in midbrain near intestinal nucleus of Cajal. J Neurophysiol 46:549-562. Medline

Klier EM, Wang H, Constantin AG, Crawford JD (2002) Midbrain control of three-dimensional head orientation. Science 295:1314-1316. CrossRef Medline

Klier EM, Wang H, Crawford JD (2007) Interstitial nucleus of Cajal encodes 
three-dimensional head orientations in Fick-like coordinates. J Neurophysiol 97:604-617. CrossRef Medline

LeDoux MS, Brady KA (2003) Secondary cervical dystonia associated with structural lesions of the central nervous system. Mov Disord 18:60-69. CrossRef Medline

Leigh RJ, Zee DS (2006) The neurology of eye movements. New York: Oxford Publishing.

Lekhel H, Popov K, Anastasopoulos D, Bronstein A, Bhatia K, Marsden CD, Gresty M (1997) Postural responses to vibration of neck muscles in patients with idiopathic torticollis. Brain 120:583-591. CrossRef Medline

Liao K, Kumar AN, Han YH, Grammer VA, Gedeon BT, Leigh RJ (2005) Comparison of velocity waveforms of eye and head saccades. Ann N Y Acad Sci 1039:477-479. CrossRef Medline

Luschei ES, Fuchs AF (1972) Activity of brain stem neurons during eye movements of alert monkeys. J Neurophysiol 35:445-461. Medline

Malmström EM, Karlberg M, Fransson PA, Lindbladh J, Magnusson M (2009) Cervical proprioception is sufficient for head orientation after bilateral vestibular loss. Eur J Appl Physiol 107:73-81. CrossRef Medline

Malouin F, Bédard PJ (1982) Frontal torticollis (head tilt) induced by electrolytic lesion and kainic acid injection in monkeys and cats. Exp Neurol 78:551-560. CrossRef Medline

Morales-Garcia C, Cardenas JL, Arriagada C, Otte J (1978) Clinical significance of rebound nystagmus in neuro-otological diagnosis. Ann Otol Rhinol Laryngol 87:238-242. Medline

Münchau A, Bronstein AM (2001) Role of the vestibular system in the pathophysiology of spasmodic torticollis. J Neurol Neurosurg Psychiatry 71:285-288. CrossRef Medline

Münchau A, Corna S, Gresty MA, Bhatia KP, Palmer JD, Dressler D, Quinn NP, Rothwell JC, Bronstein AM (2001) Abnormal interaction between vestibular and voluntary head control in patients with spasmodic torticollis. Brain 124:47-59. CrossRef Medline

Nedzelski JM (1983) Cerebellopontine angle tumors: bilateral flocculus compression as cause of associated oculomotor abnormalities. Laryngoscope 93:1251-1260. Medline

Neychev VK, Gross RE, Lehéricy S, Hess EJ, Jinnah HA (2011) The functional neuroanatomy of dystonia. Neurobiol Dis 42:185-201. CrossRef Medline

Pal PK, Samii A, Schulzer M, Mak E, Tsui JK (2000) Head tremor in cervical dystonia. Can J Neurol Sci 27:137-142. Medline

Pastor AM, De la Cruz RR, Baker R (1994) Eye position and eye velocity integrators reside in separate brainstem nuclei. Proc Natl Acad Sci U S A 91:807-811. CrossRef Medline

Peng GC, Hain TC, Peterson BW (1996) A dynamical model for reflex activated head movements in the horizontal plane. Biol Cybern 75:309-319. CrossRef Medline
Peterson BW (2004) Current approaches and future directions to understanding control of head movement. Prog Brain Res 143:369-381. Medline

Peterson BW, Goldberg J, Bilotto G, Fuller JH (1985) Cervicocollic reflex: its dynamic properties and interaction with vestibular reflexes. J Neurophysiol 54:90-109. Medline

Robinson DA (1968) Eye movement control in primates. The oculomotor system contains specialized subsystems for acquiring and tracking visual targets. Science 161:1219-1224. CrossRef Medline

Robinson DA (1974) The effect of cerebellectomy on the cat's vestibuloocular integrator. Brain Res 71:195-207. CrossRef Medline

Robinson DA (1981) The use of control systems analysis in the neurophysiology of eye movements. Annu Rev Neurosci 4:463-503. CrossRef Medline

Rondot P, Marchand MP, Dellatolas G (1991) Spasmodic torticollis-review of 220 patients. Can J Neurol Sci 18:143-151. Medline

Sano K, Yoshioka M, Mayanagi Y, Sekino H, Yoshimasu N (1970) Stimulation and destruction of and around the interstitial nucleus of Cajal in man. Confin Neurol 32:118-125. CrossRef Medline

Sano K, Sekino H, Tsukamoto Y, Yoshimasu N, Ishijima B (1972) Stimulation and destruction of the region of the interstitial nucleus in cases of torticollis and see-saw nystagmus. Confin Neurol 34:331-338. CrossRef Medline

Schiebler S, Schmidt A, Zittel S, Bäumer T, Gerloff C, Klein C, Münchau A (2011) Arm tremor in cervical dystonia - is it a manifestation of dystonia or essential tremor? Mov Disord 26:1789-1792. CrossRef Medline

Singer C, Velickovic M (2008) Cervical dystonia: etiology and pathophysiology. Neurol Clin 26 [Suppl 1]:9-22. Medline

Smetanin BN, Popov KY, Shlykov VY (1993) Postural responses to vibrostimulation of the neck muscle proprioceptors in man. Neurophysiology 25:86-92.

Stell R, Bronstein AM, Gresty M, Buckwell D, Marsden CD (1990) Saccadic function in spasmodic torticollis. J Neurol Neurosurg Psychiatry 53:496501. CrossRef Medline

Vasin N, Medzhidov MR, Shabalov VA (1985) Stereotaxic destruction of the interstitial nucleus of Cajal on spastic torticollis. Zh Vopr Neirokhir Im N N Burdenko 4:3-7.

Zee DS, Yee RD, Cogan DG, Robinson DA, Engel WK (1976) Ocular motor abnormalities in hereditary cerebellar ataxia. Brain 99:207-234. CrossRef Medline

Zee DS, Leigh RJ, Mathieu-Millaire F (1980) Cerebellar control of ocular gaze stability. Ann Neurol 7:37-40. CrossRef Medline

Zee DS, Yamazaki A, Butler PH, Gücer G (1981) Effects of ablation of flocculus and paraflocculus of eye movements in primate. J Neurophysiol 46:878-899. Medline 